\title{
Functional Architecture of the Rat Parasubiculum
}

\author{
Qiusong Tang, ${ }^{1 \star}$ Andrea Burgalossi, ${ }^{2 \star}$ Christian Laut Ebbesen, ${ }^{1,3 *}$ Juan Ignacio Sanguinetti-Scheck, ${ }^{1 \star}$ Helene Schmidt, ${ }^{1}$ \\ - John J. Tukker, ${ }^{1,4}$ Robert Naumann, ${ }^{1}$ Saikat Ray, ${ }^{1}$ Patricia Preston-Ferrer, ${ }^{2}$ Dietmar Schmitz, ${ }^{4}$ and Michael Brecht ${ }^{1}$ \\ ${ }^{1}$ Bernstein Center for Computational Neuroscience, Humboldt Universität zu Berlin, 10115 Berlin, Germany, ${ }^{2}$ Werner Reichardt Centre for Integrative \\ Neuroscience, 72076 Tübingen, Germany, ${ }^{3}$ Berlin School of Mind and Brain, Humboldt University of Berlin, 10115 Berlin, Germany, and ${ }^{4}$ Charité \\ Universitätsmedizin Berlin, 10117 Berlin, Germany
}

The parasubiculum is a major input structure of layer 2 of medial entorhinal cortex, where most grid cells are found. Here we investigated parasubicular circuits of the rat by anatomical analysis combined with juxtacellular recording/labeling and tetrode recordings during spatial exploration. In tangential sections, the parasubiculum appears as a linear structure flanking the medial entorhinal cortex mediodorsally. With a length of $\sim 5.2 \mathrm{~mm}$ and a width of only $\sim 0.3 \mathrm{~mm}$ (approximately one dendritic tree diameter), the parasubiculum is both one of the longest and narrowest cortical structures. Parasubicular neurons span the height of cortical layers 2 and 3 , and we observed no obvious association of deep layers to this structure. The "superficial parasubiculum" (layers 2 and 1 ) divides into $\sim 15$ patches, whereas deeper parasubicular sections (layer 3) form a continuous band of neurons. Anterograde tracing experiments show that parasubicular neurons extend long "circumcurrent" axons establishing a "global” internal connectivity. The parasubiculum is a prime target of GABAergic and cholinergic medial septal inputs. Other input structures include the subiculum, presubiculum, and anterior thalamus. Functional analysis of identified and unidentified parasubicular neurons shows strong theta rhythmicity of spiking, a large fraction of head-direction selectivity (50\%, 34 of 68), and spatial responses (grid, border and irregular spatial cells, 57\%, 39 of 68 ). Parasubicular output preferentially targets patches of calbindin-positive pyramidal neurons in layer 2 of medial entorhinal cortex, which might be relevant for grid cell function. These findings suggest the parasubiculum might shape entorhinal theta rhythmicity and the (dorsoventral) integration of information across grid scales.

Key words: anatomy; border cell; head-direction cell; medial entorhinal cortex; parasubiculum; spatial navigation

\section{Significance Statement}

Grid cells in medial entorhinal cortex (MEC) are crucial components of an internal navigation system of the mammalian brain. The parasubiculum is a major input structure of layer 2 of MEC, where most grid cells are found. Here we provide a functional and anatomical characterization of the parasubiculum and show that parasubicular neurons display unique features (i.e., strong theta rhythmicity of firing, prominent head-direction selectivity, and output selectively targeted to layer 2 pyramidal cell patches of MEC). These features could contribute to shaping the temporal and spatial code of downstream grid cells in entorhinal cortex.

\section{Introduction}

The analysis of spatial discharge patterns in hippocampal and parahippocampal brain regions is a remarkable success story

\footnotetext{
Received Oct. 13, 2015; revised Jan. 11, 2016; accepted Jan. 13, 2016.

Author contributions: Q.T., A.B., C.L.E., J.I.S.-S., and M.B. designed research; Q.T., A.B., C.L.E., J.I.S.-S., H.S., J.J.T., R.N., S.R., P.P.-F., D.S., and M.B. performed research; Q.T., A.B., C.L.E., J.I.S.-S., H.S., J.J.T., R.N., S.R., P.P.-F., D.S., and M.B. analyzed data; Q.T., A.B., C.L.E., J.I.S.-S., H.S., J.J.T., R.N., S.R., P.P.-F., D.S., and M.B. wrote the paper.

This work was supported by Humboldt-Universität zu Berlin, BCCN Berlin (German Federal Ministry of Education and Research BMBF, Förderkennzeichen 01GQ1001A), NeuroCure, Neuro-Behavior ERC Grant, Deutsche Forschungsgemeinschaft Gottfried Wilhelm Leibniz Prize, and the Werner Reichardt Centre for Integrative Neuroscience at the Eberhard Karls University of Tübingen. The Centre for Integrative Neuroscience is an Excellence Cluster funded by the Deutsche Forschungsgemeinschaft within the framework of the Excellence Initiative (EXC307). We thank Moritz von Heimendahl for programming; Falko Fuhrmann and Stefan Remy for generous donations of PV-Cre mice and help with the AAV injections; Susanne Schoch (University of Bonn) for providing the virus; and Andreea Neukirchner, Juliane Steger, Alexandra Eritja, Susanne Rieckmann, and Undine Schneeweiß for outstanding technical assistance. The authors declare no competing financial interests.

${ }^{*} Q$.T., A.B., C.L.E., and J.I.S.-S. contributed equally to this work.
}

(Moser et al., 2008; Moser and Moser, 2013; Burgess, 2014). Extracellular recordings revealed an astonishing degree of complexity, abstractness, but also identified clear behavioral correlates of discharge patterns, such as place, head-direction, border, and grid cells. Along with the exploration of discharge properties, anatomists delineated in great detail the basic circuitry of the

Correspondence should be addressed to either of the following: Dr. Andrea Burgalossi, Werner Reichardt Centre for Integrative Neuroscience, Otfried-Müller-Str. 25, 72076 Tübingen, Germany, E-mail: andrea.burgalossi@cin.uni-tuebingen.de; or Dr. Michael Brecht, Bernstein Center for Computational Neuroscience, Humboldt Universität zu Berlin, Philippstr. 13, Haus 6, 10115 Berlin, Germany, E-mail: michael.brecht@bccn-berlin.de.

R. Naumann's current address: Max-Planck-Institute for Brain Research, Max-von-Laue-Str. 4, 60438 Frankfurt am Main, Germany.

DOI:10.1523/JNEUROSCI.3749-15.2016

Copyright $\odot 2016$ the authors $\quad 0270-6474 / 16 / 362289-13 \$ 15.00 / 0$ 
hippocampal formation (Amaral and Witter, 1989; van Strien et al., 2009).

The detailed data available about certain parts of the hippocampal formation, such as dorsal CA1 in the rodent, should not blind us for gaps in our knowledge about less "classic" hippocampal processing nodes. The parasubiculum is one such structure that lies beyond the classic trisynaptic hippocampal loop (Andersen et al., 1971) and has been investigated relatively little. This parahippocampal region provides massive input to layer 2 of medial entorhinal cortex (van Groen and Wyss, 1990; Caballero-Bleda and Witter, 1993, 1994) and shows prominent expression of markers for cholinergic activity (Slomianka and Geneser, 1991). Early physiological analysis described a small fraction of place-responsive cells in the parasubiculum (Taube, 1995), and subsequent extracellular recordings have also identified head-direction, border, and grid responses among parasubicular neurons (Cacucci et al., 2004; Boccara et al., 2010).

From both a physiological and an anatomical perspective, the parasubiculum is somewhat difficult to study. First, the small size of the parasubiculum complicates recordings and tracer injections. Second, the parasubicular position (on the caudal edge of the parahippocampal lobe wrapping around entorhinal cortex, which goes along with a strong bending of the cortical sheet) greatly complicates the delineation of the parasubiculum. Here we aimed for a comprehensive description of parasubicular circuits by a combined anatomical and functional approach (Burgalossi et al., 2011; Tang et al., 2014a). Specifically, we were interested in how parasubicular circuits relate to pyramidal and stellate neuron microcircuits in layer 2 of medial entorhinal cortex (MEC) (Ray et al., 2014; Tang et al., 2014b).

In our current analysis, we investigate four issues: First, we delineate the location, shape, laminar organization, and internal structure of parasubiculum. Second, we investigate the sources of parasubicular inputs, as well as the targets of parasubicular outputs. Third, we assess spatial discharge patterns of parasubicular neurons by juxtacellular recording/labeling and tetrode recordings in freely moving rats. Fourth, we assess the temporal discharge patterns of identified and unidentified parasubicular neurons, and how this might relate to anatomical connectivity.

\section{Materials and Methods}

All experimental procedures were performed according to the German guidelines on animal welfare under the supervision of local ethics committees.

Brain tissue preparation. For anatomy experiments, male and female Wistar rats $(150-400 \mathrm{~g})$ were anesthetized by isoflurane and then killed by an intraperitoneal injection of $20 \%$ urethane or sodium pentobarbital. They were then perfused transcardially with $0.9 \%$ PBS solution, followed by $4 \%$ PFA in $0.1 \mathrm{~m}$ phosphate buffer (PB). After perfusion, brains were removed from the skull and postfixed in PFA overnight. They were then transferred into a $10 \%$ sucrose solution in $\mathrm{PB}$ and left overnight, and subsequently immersed in $30 \%$ sucrose solution for at least $24 \mathrm{~h}$ for cryoprotection. The brains were embedded in Jung Tissue Freezing Medium and subsequently mounted on the freezing microtome to obtain 20 - to $60-\mu \mathrm{m}$-thick sagittal sections or tangential sections (parallel to the pial surface of the MEC). Tangential sections were obtained by removing the cerebellum, visually identifying the pial surface of the MEC (Ray et al., 2014; their Fig. 1A), and making a cut $3 \mathrm{~mm}$ anterior and parallel to the pial surface of the medial entorhinal cortex. The tissue was then frozen and positioned with the pial side to the block face of the microtome.

Tissue from PV-Cre mice, expressing Cre recombinase under the parvalbumin (PV) promoter (B6;129P2-Pvalbtm1(cre)Arbr/J mice, stock \#008069, The Jackson Laboratory), was prepared using similar methods, except that the sections were cut on a standard microtome (nominal thickness $100 \mu \mathrm{m}$, horizontal) right after overnight fixation in PFA.

Histochemistry and immunohistochemistry. Acetylcholinesterase activity was visualized according to previously published procedures (Ray et al., 2014). After washing brain sections in a solution containing $1 \mathrm{ml}$ of $0.1 \mathrm{M}$ citrate buffer, $\mathrm{pH} 6.2$, and $9 \mathrm{ml} 0.9 \% \mathrm{NaCl}$ saline solution (CS), sections were incubated with $\mathrm{CS}$ containing $3 \mathrm{~mm} \mathrm{CuSO}_{4}, 0.5$ $\mathrm{mMK}_{3} \mathrm{Fe}(\mathrm{CN})_{6}$, and $1.8 \mathrm{~mm}$ acetylthiocholine iodide for $30 \mathrm{~min}$. After rinsing in $\mathrm{PB}$, reaction products were visualized by incubating the sections in $\mathrm{PB}$ containing $0.05 \%$ 3, $3^{\prime}$ - DAB and $0.03 \%$ nickel ammonium sulfate. Immunohistochemical stainings were performed according to standard procedures. Briefly, brain sections were preincubated in a blocking solution containing 0.1 м PBS, $2 \%$ BSA, and $0.5 \%$ Triton X-100 (PBS-X) for an hour at room temperature. Following this, primary antibodies were diluted in a solution containing PBS-X and $1 \%$ BSA. We used primary antibodies against the calcium binding protein Calbindin (1:5000), the DNA binding neuron-specific protein NeuN (1:1000), and, for the mice, against GFP. Incubations with primary antibodies were allowed to proceed for at least $24 \mathrm{~h}$ under mild shaking at $4^{\circ} \mathrm{C}$ in freefloating sections. Incubations with primary antibodies were followed by detection with secondary antibodies coupled to different fluorophores (Alexa-488 and Alexa-546). Secondary antibodies were diluted (1:500) in PBS-X, and the reaction was allowed to proceed for $2 \mathrm{~h}$ in the dark at room temperature. For multiple antibody labeling, antibodies raised in different host species were used. After the staining procedure, sections were mounted on gelatin-coated glass slides with Mowiol or Vectashield mounting medium. In a subset of experiments, primary antibodies were visualized by $\mathrm{DAB}$ staining. For this purpose, endogenous peroxidases were first blocked by incubating brain tissue sections in methanol containing $0.3 \%$ hydrogen peroxide in the dark at room temperature for 30 min. The subsequent immunohistochemical procedures were performed as described above, with the exception that detection of primary antibodies was performed by biotinylated secondary antibodies and the $\mathrm{ABC}$ detection kit. Immunoreactivity was visualized using DAB staining.

The relative density of putative parvalbuminergic fibers in PV-Cre mice in hippocampus CA1-3, presubiculum, parasubiculum, and medial entorhinal cortex was estimated by manually outlining these four areas (Paxinos and Franklin, 2012) in epifluorescence images $(2.5 \times)$ from horizontal sections (estimated depth $3 \mathrm{~mm}$ relative to bregma) and then measuring mean fluorescence signals in each area with the ImageJ software. For comparison between brains, these values were then normalized to the mean hippocampal value in each brain $(n=3)$.

Anterograde and retrograde neuronal labeling. Anterograde or retrograde tracer solutions containing biotinylated dextrane amine (BDA) $(10 \% \mathrm{w} / \mathrm{v} ; 3000$ or 10,000 molecular weight $)$ were injected in juvenile rats $(\sim 150 \mathrm{~g})$ under ketamine/xylazine anesthesia. Briefly, a small craniotomy was opened above the parasubiculum/medial entorhinal cortex. Before injection, the parasubiculum was localized by electrophysiological recordings, based on cortical depth, characteristic signatures of the local field potential theta oscillations, and neuronal spiking activity. Glass electrodes with a tip diameter of $10-20 \mu \mathrm{m}$, filled with BDA solution, were then lowered into the target region. Tracers were either pressure-injected ( 10 injections using positive pressure of $20 \mathrm{psi}, 10-15 \mathrm{~s}$ injection duration) or iontophoretically injected (7 s on/off current pulses of 1-5 mA for $15 \mathrm{~min}$ ). After the injections, the pipettes were left in place for several minutes and slowly retracted. The craniotomies were closed by application of silicone and dental cement. The animals survived for 3-7 d before being transcardially perfused.

Viral injections and quantification of anterorgradely traced axons. PV-Cre mice, expressing Cre recombinase under the PV promoter (B6;129P2-Pvalbtm1(cre)Arbr/J mice, stock \#008069, The Jackson Laboratory) were injected with AAV-Efla-dbf-hChR2(H134R)-EYFPWPRE (serotype 1/2) $\sim 6$ weeks before perfusion. The medial septum was targeted under stereotaxic guidance: starting from the pial surface at 1 $\mathrm{mm}$ anterior, $0.7 \mathrm{~mm}$ right lateral to bregma, a 34-gauge NanoFil needle (WPI) was advanced at an angle of $10^{\circ}$ in the coronal plane for 4200 and $4600 \mu \mathrm{m}$, where we injected $1 \mu \mathrm{l}$ each $(100 \mathrm{nl} / \mathrm{s})$, waiting $5 \mathrm{~min}$ after each injection before moving the needle. The AAV virus was generously provided to us by Susanne Schoch (University of Bonn). 
Fluorescence signals were normalized to dentate gyrus intensity levels and quantified. Briefly, regions of interests from horizontal sections (at a depth of $\sim 3.5 \mathrm{~mm}$ ventral to bregma) (Paxinos and Franklin, 2012) were manually outlined and the mean fluorescence intensity for each area quantified using the ImageJ software $(n=3$ mice).

Juxtacellular recordings. Juxtacellular recordings and tetrode recordings in freely moving animals were obtained in male Wistar and LongEvans rats (150-250 g). Experimental procedures were performed as recently described (Tang et al., 2014a, b, 2015). Briefly, rats were maintained in a $12 \mathrm{~h}$ light/dark phase and were recorded in the dark phase. Glass pipettes with resistance $4-6 \mathrm{M} \Omega$ were filled with extracellular Ringer's solution containing (in $\mathrm{mm}$ ) the following: $135 \mathrm{NaCl}, 5.4 \mathrm{KCl}, 5$ HEPES, $1.8 \mathrm{CaCl}_{2}$, and $1 \mathrm{MgCl}_{2}, \mathrm{pH} 7.2$, and Neurobiotin (1\%-2\%). Animal implantations were performed as previously described (Tang et al., 2014a). To target the parasubiculum, a plastic ring was placed $0.2-0.5$ $\mathrm{mm}$ anterior to the transverse sinus and $4.0-4.5 \mathrm{~mm}$ lateral to the midline. After implantation, rats were allowed to recover from the surgery and were habituated to head fixation for 3-5 $\mathrm{d}$. Rats were trained in the experimental arena $(70 \times 70 \mathrm{~cm}$ or $1 \times 1 \mathrm{~m}$ square black box, with a white cue card on the wall) for 3-7 d. Juxtacellular recordings and labeling were essentially performed as previously described (Tang et al., 2014a; Pinault, 1996). Unidentified recordings in parasubiculum were either lost before the labeling could be attempted, or the recorded neurons could not be unequivocally identified; but either pipette tracks or dendritic processes were found in the parasubiculum. After the experiment, the animals were killed with an overdose of ketamine, urethane, or sodium pentobarbital, and perfused transcardially with $0.1 \mathrm{M}$ PB followed by $4 \%$ PFA solution, shortly after the labeling protocol. The juxtacellular signals were amplified by the ELC-03XS amplifier (NPI Electronics) and sampled at $20 \mathrm{kHz}$ by a data-acquisition interface under the control of PatchMaster 2.20 software (HEKA). The animal's location and head-direction were automatically tracked at $25 \mathrm{~Hz}$ by the Neuralynx video-tracking system and two head-mounted LEDs. MEC data for comparison have been published previously (Ray et al., 2014; Tang et al., $2014 b, 2015)$. One head-direction cell recorded and identified in the parasubiculum has been shown in a previous paper (Tang et al., 2014a).

Tetrode recordings. Tetrode recordings from parasubiculum were essentially performed as recently described (Tang et al., 2014b, 2015). Tetrodes were turned from 12.5- $\mu \mathrm{m}$-diameter nichrome wire (California Fine Wire) and gold plated to $\sim 250 \mathrm{k} \Omega$ impedance. Spiking activity and local field potential were recorded at $32 \mathrm{kHz}$ (Neuralynx; Digital Lynx). The local field potential was recorded from the same tetrode as single units and referenced to a superficial silent neocortical tetrode or to the rat ground. All recordings were performed following behavioral training, as specified above for juxtacellular procedures. The animal's location and head-direction were automatically tracked at $25 \mathrm{~Hz}$ by video tracking and head-mounted LEDs, as described above. After recordings, tetrodes were retracted from the parahippocampal areas, and multiple lesions were performed at distinct sites along the individual tetrode tracks, thereby allowing unequivocal assignment of the different tetrode tracks. Following perfusion, brains were sectioned tangentially and recording sites assigned by histology. Spikes were preclustered using KlustaKwik (K.D. Harris, Rutgers University) and manually using MClust (A.D. Redish, University of Minnesota). Cluster quality was assessed by spike shape, ISI-histogram, L-ratio, and isolation distance.

Neurobiotin labeling and calbindin immunohistochemistry. For histological analysis of juxtacellularly labeled neurons, Neurobiotin was visualized with streptavidin conjugated to Alexa-546 (1:1000). Subsequently, immunohistochemistry for Calbindin was performed, as previously described (Ray et al., 2014), and visualized with AlexaFluor-488. After fluorescence images were acquired, the Neurobiotin staining was converted into a dark DAB reaction product. Neuronal morphologies were reconstructed by computer-assisted manual reconstructions (Neurolucida).

Analysis of theta rhythmicity. Theta rhythmicity of spiking discharge was determined from the Fast Fourier Transform-based power spectrum of the spike-train autocorrelation functions of the neurons, binned at 10 $\mathrm{ms}$. To measure modulation strength in the theta band $(4-12 \mathrm{~Hz})$, a theta power was computed, defined as the average power within $1 \mathrm{~Hz}$ of the maximum of the autocorrelation function in the theta rhythm $(4-12$
$\mathrm{Hz}$ ). This is referred to here as theta rhythmicity. Only neurons with mean firing rate $>0.5 \mathrm{~Hz}$ were included in the theta analysis. Statistical significance between groups was assessed by two-tailed Mann-Whitney nonparametric test with 95 th confidence intervals.

Analysis of theta locking. For all neurons, we calculated the locking to theta phase based on spiking discharge in relation to theta rhythm in the local field potential. The local field potential was zero phase bandpass filtered $(4-12 \mathrm{~Hz})$, and a Hilbert transform was used to determine the instantaneous phase of the theta wave. In line with previous studies (Mizuseki et al., 2009), the theta phase locking strength, $S$, and the preferred phase angle, $\varphi$, were defined as the modulus and argument of the Rayleigh average vector of the theta phase for all spikes. The theta phase locking strength value can vary between 0 (uniform distribution of spikes over the theta cycle) and 1 (all spikes have the same theta phase). Only spikes during running (speed cutoff $=1 \mathrm{~cm} / \mathrm{s}$ for juxtacellular signals, 5 $\mathrm{cm} / \mathrm{s}$ for tetrode recordings) were included in the analysis. Only neurons with mean firing rate $\geq 0.5 \mathrm{~Hz}$ were included in the analysis. For comparison to MEC L2 data, both the analysis procedures and the juxtacellular dataset correspond to our recent publications (Ray et al., 2014; Tang et al., 2014b, 2015).

Analysis of spatial modulation. The position of the rat was defined as the midpoint between two head-mounted LEDs. A running speed threshold (see above) was applied for isolating periods of rest from active movement. Color-coded firing maps were plotted. For these, space was discretized into pixels of $2.5 \mathrm{~cm} \times 2.5 \mathrm{~cm}$, for which the occupancy $z$ of a given pixel $x$ was calculated as follows:

$$
z(x)=\sum_{t} w\left(\left|x-x_{t}\right|\right) \Delta t
$$

where $x_{t}$ is the position of the rat at time $t, \Delta t$ the interframe interval, and $w$ a Gaussian smoothing kernel with $\sigma=5 \mathrm{~cm}$.

Then, the firing rate $r$ was calculated as follows:

$$
r(x)=\frac{\sum_{i} w\left(\left|x-x_{i}\right|\right)}{z}
$$

where $x_{i}$ is the position of the rat when spike $i$ was fired. The firing rate of pixels, whose occupancy $z$ was $<20 \mathrm{~ms}$, was considered unreliable and not shown.

To determine the spatial periodicity of juxtacellularly recorded neurons, we determined spatial autocorrelations. The spatial autocorrelogram was based on Pearson's product moment correlation coefficient as follows:

$$
\begin{aligned}
r\left(\tau_{x}, \tau_{y}\right)=\frac{n \sum f(x, y) f\left(x-\tau_{x}, y-\tau_{y}\right)}{\sqrt{n \sum f(x, y)^{2}-\left(\sum f(x, y)\right)^{2}}} \\
\times \sqrt{n \sum f\left(x-\tau_{x}, y-\tau_{y}\right)^{2}-\left(\sum f\left(x-\tau_{x}, y-\tau_{y}\right)\right)^{2}}
\end{aligned}
$$

where $r\left(\tau_{x}, \tau_{y}\right)$ the autocorrelation between pixels or bins with spatial offset $\tau_{x}$ and $\tau_{\gamma}$ f is the image without smoothing or the firing rate map after smoothing, $n$ is the number of overlapping pixels or bins. Autocorrelations were not estimated for lags of $\tau_{x}$ and $\tau_{y}$, where $n<20$. For spatial and head-directional analysis, both a spatial $(>50 \%$ spatial coverage) and a firing rate inclusion criterion $(>0.5 \mathrm{~Hz})$ were applied. Spatial coverage was defined as the fraction of visited pixels (bins) in the arena to the total pixels.

Analysis of spatial information. For all neurons, we calculated the spatial information rate, $I$, from the spike train and rat trajectory as follows:

$$
l=\frac{1}{T} \int r(x) \log _{2} \frac{r(x)}{\bar{r}} o(x) d x
$$


where $r(x)$ and $o(x)$ are the firing rate and occupancy as a function of a given pixel $x$ in the rate map. $\bar{r}$ is the overall mean firing rate of the cell, and $T$ is the total duration of a recording session (Skaggs et al., 1993). A cell was determined to have a significant amount of spatial information if the observed spatial information rate exceeded the 95th percentile of a distribution of values of $I$ obtained by circular shuffling. Shuffling was performed by a circular time-shift of the recorded spike train relative to the rat trajectory by a random time $t^{\prime} \in[0, T]$ for 1000 permutations (von Heimendahl et al., 2012; Bjerknes et al., 2014).

Analysis of border cells. To determine the modulation of a cell firing along a border, we determined border scores (Solstad et al., 2008). Border fields were identified from a collection of neighboring pixels having a firing rate $>0.3$ times the maximum firing rate and covering an area of at least $100 \mathrm{~cm}$ (Sargolini et al., 2006). The coverage (Cm) along a wall was defined as the maximum length of a putative border field parallel to a boundary, divided by the length of the boundary. The mean firing distance (Dm) of a field was defined as the sum of the square of its distance from the boundary, weighted by the firing rate (Solstad et al., 2008). The distance from a boundary was defined as the exponential of the square of the distance in pixels from the closest boundary, normalized by half the length of the boundary. Border scores were defined as the maximum difference between $\mathrm{Cm}$ and $\mathrm{Dm}$, divided by their sum, and ranged from -1 to 1 .

Analysis of grid cells. Grid scores were calculated, as previously described (Barry et al., 2012), by taking a circular sample of the autocorrelogram, centered on, but excluding the central peak. The Pearson correlation of this circle with its rotation for 60 degrees and 120 degrees was obtained (on peak rotations) and also for rotations of 30,90 , and 150 degrees (off peak rotations). Gridness was defined as the minimum difference between the on-peak rotations and off-peak rotations. To determine the grid scores, gridness was evaluated for multiple circular samples surrounding the center of the autocorrelogram with circle radii increasing in unitary steps from a minimum of 10 pixels more than the width of the radius of the central peak to the shortest edge of the autocorrelogram. The radius of the central peak was defined as the distance from the central peak to its nearest local minima in the spatial autocorrelogram. The radius of the inner circle was increased in unitary steps from the radius of the central peak to 10 pixels less than the optimal outer radius. The grid score was defined as the best score from these successive samples. Grid scores reflect both the hexagonality in a spatial field and also the regularity of the hexagon. To disentangle the effect of regularity from this index and consider only hexagonality, we transformed the elliptically distorted hexagon into a regular hexagon and computed the grid scores (Barry et al., 2012). A linear affine transformation was applied to the elliptically distorted hexagon, to stretch it along its minor axis, until it lay on a circle, with the diameter equal to the major axis of the elliptical hexagon. The grid scores were computed on this transformed regular hexagon (Barry et al., 2012).

Analysis of head-directionality. Head-direction tuning was measured as the eccentricity of the circular distribution of firing rates. For this, firing rate was binned as a function of head-direction ( $n=36$ bins). A cell was said to have a significant head-direction tuning if the length of the average vector exceeded the 95 th percentile of a distribution of average vector lengths calculated from shuffled data and had a Rayleigh vector length $>0.3$. Data were shuffled by applying a random circular time-shift to the recorded spike train for 1000 permutations.

Classification of cells into functional categories. Cells were classified as head-direction cells, grid cells, conjunctive cells, border cells, spatially irregular cells, and nonspatially modulated cells, based on their grid score, border score, spatial information, and significance of headdirectionality according to the following criteria: head-direction cells, Rayleigh vector length $>0.3$, and significant head-direction tuning (Boccara et al., 2010); grid cells, grid score $>0.3$, and significant spatial information; border cells, border score $>0.5$, and significant spatial information (Solstad et al., 2008), or those who passed border test (Lever et al., 2009); spatially irregular cells, significant spatial information (Bjerknes et al., 2014), while not passing grid score or border score criteria; and nonspatially modulated cell, no significant spatial information.

\section{Results}

\section{Geometry of the parasubiculum}

In our initial analysis, we sought to determine the general organization of the parasubiculum. Tangential sections (parallel to the pial surface of the MEC; see Materials and Methods) of the cortical sheet stained for acetylcholine esterase activity (Fig. $1 A$, left) or calbindin immunoreactivity (Fig. $1 A$, right) provide a particularly clear overview of the spatial extent of the parasubiculum. Consistent with findings from previous studies (Geneser, 1986; Slomianka and Geneser, 1991), we find that the parasubiculum shows prominent acetylcholine esterase activity (Fig. $1 A$, left). The parasubiculum can also be identified by an absence of calbindin immunoreactivity (Fig. 1A, left) (Fujise et al., 1995; Boccara et al., 2010). Further subdivisions of the parasubiculum have been suggested (Blackstad, 1956). Our data refer to the calbindin free area surrounding the MEC outlined in Figure 1A, left and highlighted in light blue in Figure $1 B$ [possibly related to "parasubiculum b" in the terminology of Blackstad (1956)]. Laterally contiguous to the parasubiculum one observes a thin strip of cortex containing numerous calbindin-positive neurons (Fig. $1 A$, right, $B$, red "calbindin stripe").

As shown in Figure $1 A, B$ and quantified in Figure $1 C$, the parasubiculum forms a fairly narrow $(310 \pm 83 \mu \mathrm{m}$ width, $N=10)$, but very elongated ( $5.190 \pm 0.485 \mathrm{~mm}$ length, $N=10$ ) continuous curved stripe, which flanks the medial entorhinal cortex from its medial to dorsolateral side. The lateral part of the parasubiculum, dorsal to the medial entorhinal cortex, is narrower than the medial part. This may explain why this part of the parasubiculum has not been classified as such in most previous studies (Boccara et al., 2010; Ding, 2013). Other histological markers, such as cytochrome-oxidase activity, or soma morphologies, as visualized from Nissl stains (Burgalossi et al., 2011), also delineated the parasubiculum in the same way as shown in Figure 1 (data not shown). Similarly, parasagittal sectioning angles delineate the same outlines of the parasubiculum. We conclude that the parasubiculum has a linear structure with a narrow width.

We also investigated the laminar structure of the parasubiculum. Consistent with our previous conclusions (Burgalossi et al., 2011), we did not find direct evidence for a clear association of deep layers with the parasubiculum. For example, following tracer injections in the superficial parasubicular layers, we did not observe back-labeled neurons in the adjacent deep layers, even when we observed back-labeled neurons as distant as the subiculum (data not shown). Hence, we speculate that deep layers close to the parasubiculum might not be part of this structure but could rather be associated with the neighboring medial entorhinal cortex or the presubiculum (Mulders et al., 1997).

\section{Internal structure of the parasubiculum}

Consistent with our previous observations (Burgalossi et al., 2011), we found the superficial parts of the parasubiculum (corresponding to layers 1 and 2) can be divided into $\sim 15$ large patches with a diameter $\sim 500 \mu \mathrm{m}$ each. These patches can be revealed in superficial tangential sections (Fig. $1 D$, left) by PV immunoreactivity and by cell density visualized by NeuN immunoreactivity (Fig. $1 D$, right). However, the deeper parts of the parasubiculum (corresponding to layer 3) were not obviously divided into patches (Fig. 1D).

Injections of the anterograde tracer BDA (3000 molecular weight) showed that parasubicular neurons extend long axons throughout the full length of the parasubiculum (Fig. 1E), consistent with previous evidence from single-cell microcircuits (Burgalossi et al., 2011). In the latter work, these axons were 

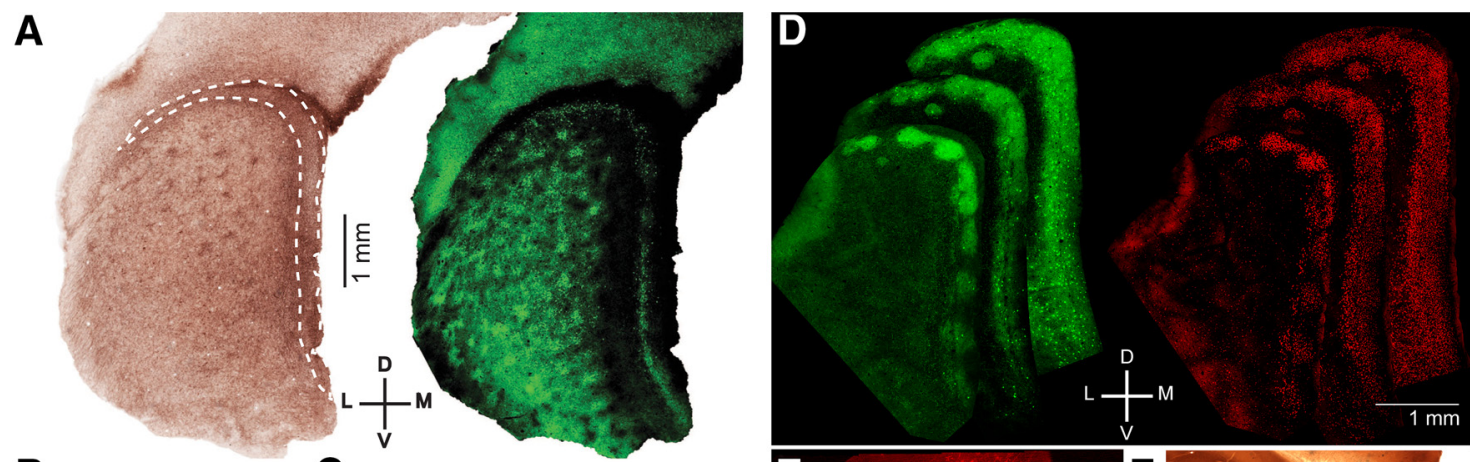

B

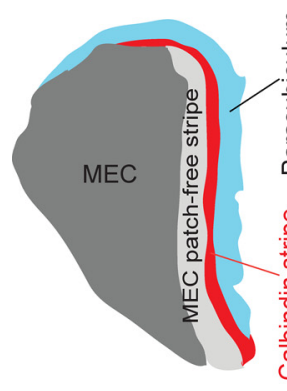

C

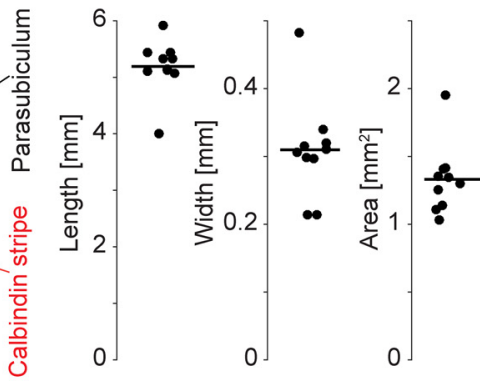

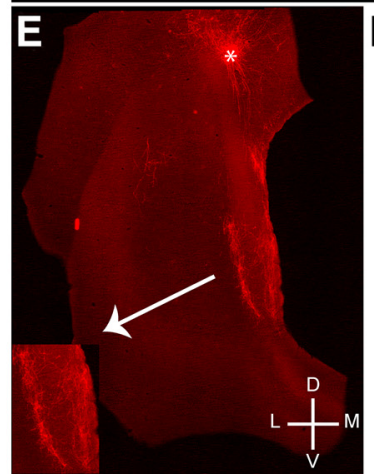

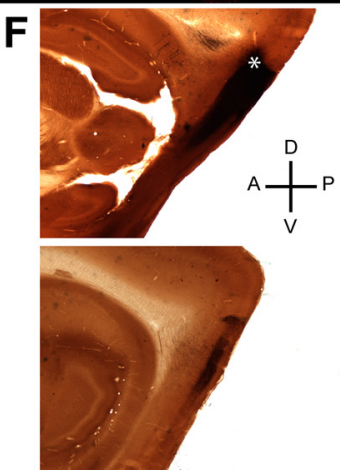

Figure 1. Shape and internal structure of the parasubiculum. $\boldsymbol{A}$, Left, Tangential section stained for acetylcholinesterase activity (dark precipitate). The shape of the parasubiculum is outlined (white dashed line) coinciding with high acetylcholinesterase activity. Right, Tangential section (same section as in $\boldsymbol{A}$, left) processed for calbindin immunoreactivity (green); the shape of the parasubiculum is negatively outlined by an absence of calbindin immunoreactivity. $\boldsymbol{B}$, Schematic of the parasubiculum (light blue) and adjacent MEC subdivisions. $\boldsymbol{C}$, Quantification of parasubiculum size in 10 hemispheres: length, width, and area. $\boldsymbol{D}$, Tangential sections stained for PV immunoreactivity (green, left) and NeuN immunoreactivity (red, right). The parasubiculum stands out by its intense staining. Three sections are shown: left, most superficial (closest to the pia); middle and right, progressively deeper. Note how the patchy structure of the superficial parasubiculum is replaced by a continuous cell band in deeper sections. $\boldsymbol{E}$, Tangential sections of the parasubiculum showing the injection site of BDA tracer (red fluorescence) and anterogradely traced circumcurrent axons (according to the terminology of Burgalossi et al., 2011), extending throughout the parasubiculum (see also magnified inset, left). *Injection site. $\boldsymbol{F}$, Parasagittal sections of the parasubiculum (top) and parasubiculum and MEC (bottom) after the injection of larger amounts of BDA (tracer, dark color). The tracer completely fills the parasubiculum and stains layer 2 of the MEC. *Injection site. $A$, B, Modified from Ray et al. (2014). D, Dorsal; L, lateral; M, medial; V, ventral; A, anterior; P, posterior.

termed "circumcurrent," as they appeared to interconnect parasubicular patches. As a consequence of this internal connectivity, a single tracer injection could label the full extent of the parasubiculum (Fig. $1 F$ ). This is a remarkable feature of the parasubiculum not seen in the medial entorhinal cortex. Thus, analysis of the internal structure of parasubiculum indicates both modularity and global connectivity.

\section{Inputs to the parasubiculum}

Of particular interest for hippocampal function are the inputs from the medial septum, which are of critical importance to grid cell activity (Brandon et al., 2011; Koenig et al., 2011). We first sought to determine the patterns of GABAergic inputs from the medial septum, which are thought to play a critical role in thetarhythm generation (Mitchell et al., 1982; Buzsáki, 2002; Hangya et al., 2009; Brandon et al., 2011; Koenig et al., 2011). To this end, we performed viral injections in the medial septum in PV-Cre mice (see Materials and Methods) and expressed GFP selectively in GABAergic septal neurons (Fig. 2A,B). As shown in Figure 2A, the parasubiculum is an area within the hippocampal formation, which receives a comparatively dense innervation from GABAergic medial septal neurons (as quantified by normalized fluorescence levels, mean values $[n=3$ ], parasubiculum $=1.5 \pm 0.23$, $\mathrm{MEC}=1.0 \pm 0.05, \mathrm{CA} 1-3=1.2 \pm 0.06$, PreS $=1.0 \pm 0.04$; Fig. $2 C$ ). As we already noted earlier, there is also a prominent expression of cholinergic activity markers (Figs. 1A, 2D) in line with in vitro work showing robust response of parasubicular neurons to muscarinic activation (Glasgow and Chapman, 2013). Together, these data point toward a strong medial septal drive to parasubicular neurons, likely contributing to strong theta rhythmicity in the parasubiculum (Burgalossi et al., 2011; see below).

By retrograde-tracer injections, we also identified parasubiculum-projecting neurons in the anterior thalamus, subiculum, and presubiculum. The findings are consistent with the earlier conclusions of previous authors (Köhler, 1985; van Groen and Wyss, 1992; Honda and Ishizuka, 2004) and are therefore not shown.

\section{Outputs from the parasubiculum}

Previous work showed that the parasubicular axons innervate layer 2 of the medial entorhinal cortex (van Groen and Wyss, 1990; Caballero-Bleda and Witter, 1993, 1994; but see Canto et al., 2012). Recent work showed that principal neurons in layer 2 of medial entorhinal cortex segregate into stellate and pyramidal cell subnetworks, which can be differentiated by the calbindin immunoreactivity of the pyramidal neurons (Varga et al., 2010). Layer 2 pyramidal neurons are arranged in a hexagonal grid, show strong theta-rhythmic discharges (Ray et al., 2014), and might preferentially contribute to the grid cell population (Tang et al., 2014b; but see Sun et al., 2015). To determine whether parasubicular inputs target a specific subpopulation of neurons in layer 2 of medial entorhinal cortex, we performed fine-scale injections of anterograde tracers in the dorsal parasubiculum, combined with visualization of calbindin patterns (Fig. 3). As shown in Figure 3, tangential sections through layer 2 with calbindin immunostaining revealed a regular organization of patches of pyramidal neurons (Ray et al., 2014). Surprisingly, 


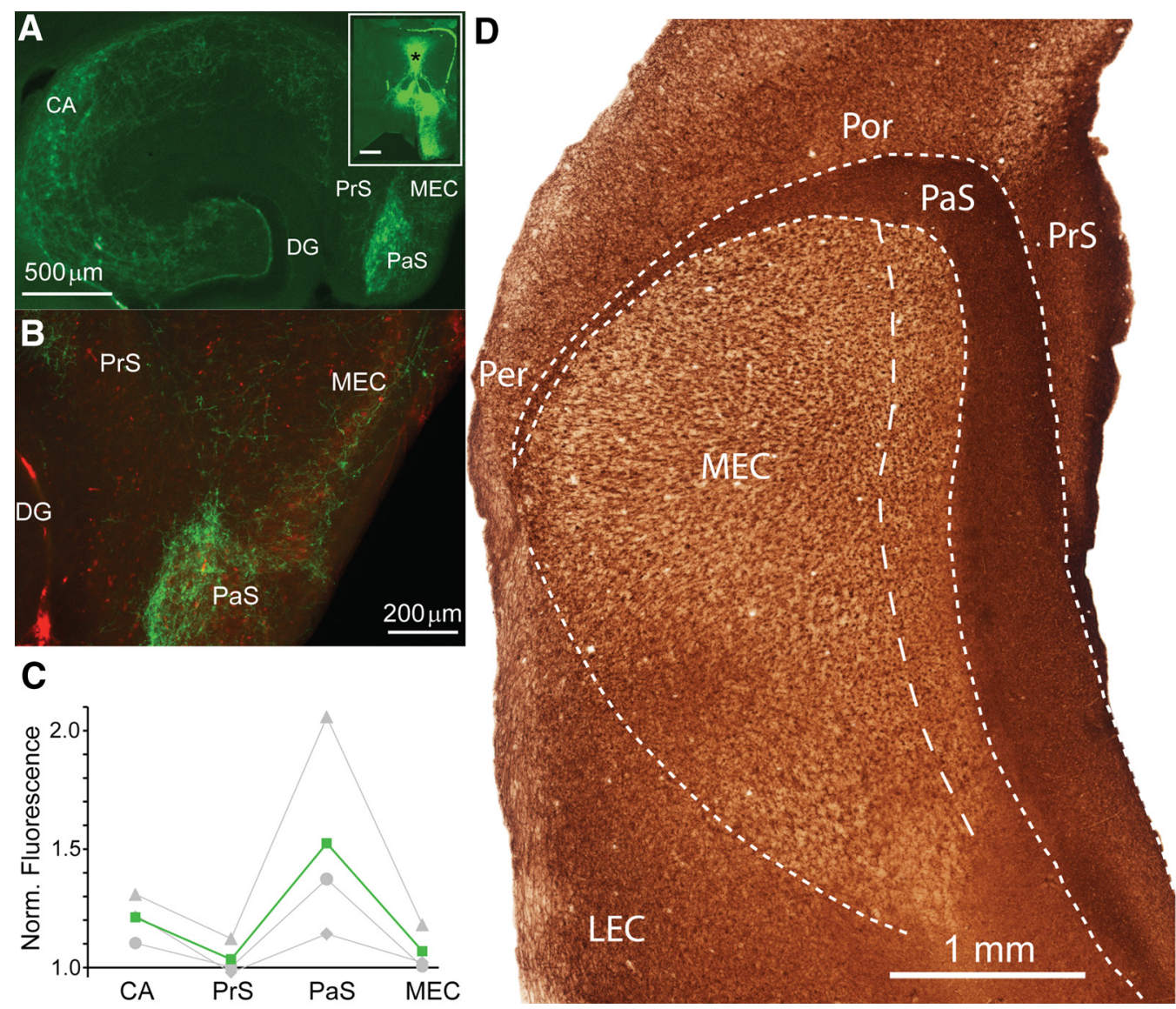

Figure 2. Parasubiculum receives GABAergic and cholinergic inputs. $A$, Horizontal sections showing that the parasubiculum contains the densest projection in the hippocampal formation of GFP-positive, putative parvalbuminergic fibers deriving from injection of AAV into the medial septum (inset, asterisk) of mice expressing Cre recombinase under the PV promoter. This dense projection pattern was seen in 3 of 3 injected mice. In this brain, olfactory and accessory olfactory areas were also labeled unilaterally. $\boldsymbol{B}, \mathrm{PV}$ immunostaining (red) marks the extent of the parasubiculum (as shown in Fig. 1D, left). Note the higher density of GABAergic medial septal fibers (green) within the parasubiculum. $C$, Normalized fluorescence intensity levels relative to dentate gyrus ( $n=3$ mice, different gray symbols represent the different mice). Green squares represent mean normalized fluorescence. $D$, Tangential section showing high levels of acetylcholinesterase in the parasubiculum. PrS, Presubiculum; DG, dentate gyrus; LEC, lateral entorhinal cortex; PaS, parasubiculum; Por, postrhinal cortex; Per, perirhinal cortex; CA, cornus ammonis.

these patches were selectively innervated by parasubicular afferents (Fig. $3 A, B$ ), which targeted the center of patches (Fig. $3 C)$. This indicates that parasubicular axons may preferentially target layer 2 pyramidal neurons of medial entorhinal cortex, which may in turn contribute to the strong theta rhythmicity in these neurons (Ray et al., 2014).

\section{Identification of functional cell types in the parasubiculum}

Compared with its major target structure (the entorhinal cortex), limited information is currently available about the spatial discharge properties in the parasubiculum (Taube, 1995; Cacucci et al., 2004; Boccara et al., 2010). To address this issue, we juxtacellularly recorded and labeled neurons $(n=16)$ in the parasubiculum of freely moving rats trained to explore $2 \mathrm{D}$ environments (Tang et al., 2014a) A representative recording from an identified parasubicular neuron is shown in Figure $4 A$. This neuron had divergent sideward-directed dendrites (seen from the top), was situated in the dorsal part of the parasubiculum (Fig. 4A, right), and discharged in spike bursts strongly entrained by the theta rhythm (Fig. 4B). Theta rhythmicity of spiking was revealed by the spiking autocorrelogram (Fig. $4 C$, left), and the spikes were also strongly locked to local theta oscillations (Fig. $4 C$, right). The neuron discharged along the border of the enclosure (Fig. $4 D$, left), a defining feature of border activity (Solstad et al., 2008), and showed head-direction selectivity (Fig. 4D, right).
In line with previous observations in linear mazes (Burgalossi et al., 2011), many juxtacellularly recorded neurons showed head-direction selectivity. A representative neuron is shown in Figure $4 E$. This neuron was situated in the medial part of the parasubiculum (Fig. 4E, right) and also discharged in bursts with strong theta rhythmicity (Fig. $4 F$, right). The spiking autocorrelogram also revealed a strong theta rhythmicity (Fig. $4 G$, left), and the spikes were strongly locked to local theta oscillations (Fig. 4G, right). Spikes were fired throughout the enclosure without obvious spatial modulation (Fig. $4 \mathrm{H}$, left) but showed a clear headdirection preference (Fig. $4 H$, right).

\section{Spatial firing properties of parasubicular neurons}

By combining juxtacellularly recorded and identified parasubicular neurons with verified recording sites of single-cell and tetrode recordings (see Materials and Methods), we could provide a more comprehensive characterization of functional cell types in parasubiculum. In line with previous work (Boccara et al., 2010), we observed border discharges (9\%, 6 of 68; Figs. 4D, $5 A$ ), grid discharges $(9 \%, 6$ of 68 ; Fig. $5 B)$, strong head-direction selectivity $(50 \%, 34$ of 68 ; Figs. $4 H, 5 C)$, and a substantial proportion of irregular spatial discharges (40\%, 27 of 68) (cells not shown). This last group contains cells with significant spatial information content (Skaggs et al., 1993; see Materials and Meth- 


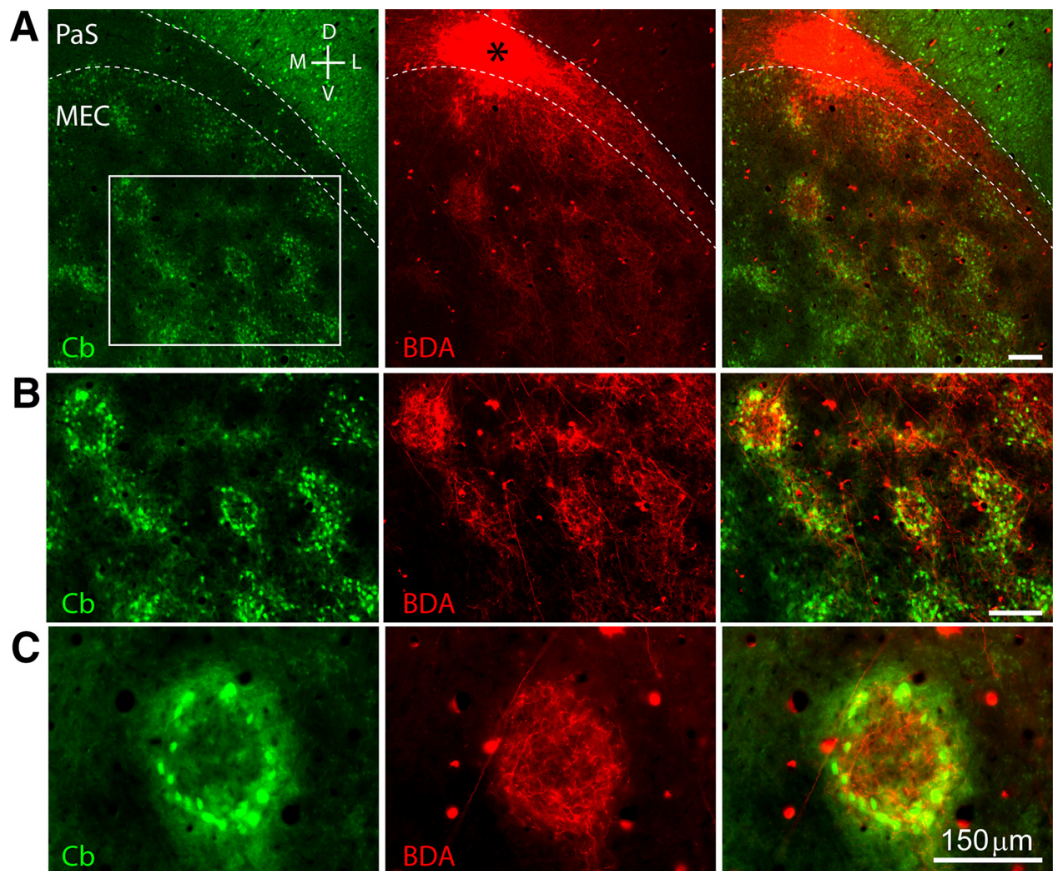

Figure 3. Parasubicular axons target layer 2 pyramidal cell patches in medial entorhinal cortex. $\boldsymbol{A}$, Left, Tangential section stained for calbindin (green) revealing patches of calbindin-positive pyramidal neurons. Middle, Same section as left processed to reveal the tracer BDA (red). * Location of the parasubicular injection site. Right, Overlay. Scale bar, $150 \mu \mathrm{m}$. B, Same as $\boldsymbol{A}$ but at higher magnification. Scale bar, $150 \mu \mathrm{m}$. C, High-magnification view of a single patch. D, Dorsal; L, lateral; M, medial; V, ventral.

ods) but that do not meet grid or border inclusion criteria (see Materials and Methods).

Next, we compared the spatial discharge properties of the parasubiculum with those of identified and putative MEC layer 2 pyramidal and stellate neurons (Tang et al., 2014b) as well as neurons recorded in MEC layer 3 (Tang et al., 2015). We found significantly more spatial responses in the parasubicular neurons than in the other cell types (Fig. $6 A$; all $p<0.01, \chi^{2}$ test with Bonferroni-Holm correction: 39 of 68 parasubiculum, $\chi^{2}=7.91$ vs 35 of 99 Pyr, $\chi^{2}=12.4$ vs 28 of 94 Stel, $\chi^{2}=11.1$ vs $19 / 66$ L3). We also observed a strong head-directionality of parasubicular neurons, in line with previous observations from linear track recordings (Burgalossi et al., 2011). At the population level, the median head-direction vector of all parasubicular neurons was 0.31 , much larger than in MEC layer 2 (0.12 in pyramidals; 0.14 in stellates) and layer 3 (0.09 in layer 3 cells; Fig. $6 B$; all $p<0.001$, Mann-Whitney $U$ tests with Bonferroni-Holm correction: $z($ Pyr $)=5.54, z($ Stel $)=5.79, z(\mathrm{~L} 3)=7.01)$. Similarly, the proportion of neurons classified as head-direction cells was also considerably larger than in MEC layers 2 and 3 (Fig. $6 C$; all $p<0.001$, $\chi^{2}$ test with Bonferroni-Holm correction: $\chi^{2}(\mathrm{Pyr})=17.7$, $\chi^{2}($ Stel $\left.)=28.8, \chi^{2}(\mathrm{~L} 3)=30.7\right)$

\section{Theta modulation of parasubicular neurons}

As shown in representative neurons (Figs. 4, 5), the large majority of parasubicular neurons showed strong theta rhythmicity, as revealed by autocorrelation of spike trains (Fig. 7A) (Tang et al., 2014b, 2015). Parasubicular neurons were also strongly locked to local field potential theta oscillations, which is known to be in phase with MEC theta (Glasgow and Chapman, 2007) (Fig. 7B). On average, theta rhythmicity was stronger in parasubicular neurons than in identified layer 2 stellates and layer 3 neurons (both $p<0.01$, Mann-Whitney $U$ test, $z($ Stel $)=3.19, z(\mathrm{~L} 3)=8.39$; Fig. $7 C$; MEC cells from Tang et al., 2014b and Tang et al., 2015). Identified parasubicular neurons tended to have a higher theta rhythmicity than identified layer 2 neurons (juxtacellularly recorded cells, $p=0.0116$, MannWhitney $U$ test), but this difference did not reach statistical significance when tetrode units were included in the sample of parasubicular neurons. Theta phase locking strength (mean (circular) vector length; see Materials and Methods) of parasubicular neurons was similar to that of MEC layer 2 pyramidal neurons $(p>0.05$, Mann-Whitney $U$ test: $z=-0.89$; Fig. $7 D$ ) and significantly stronger than that of layer 2 stellates and layer 3 neurons (both $p<$ 0.001, Mann-Whitney $U$ test: $z($ Stel $)=$ 3.73, $z(\mathrm{~L} 3)=7.83$; Fig. $7 D$; MEC cells from Tang et al., 2014b, 2015).

Notably, at the population level, parasubicular and MEC layer 2 pyramidal and stellate neurons showed distinct preferred theta phases (all $p<0.05$, Rayleigh test for nonuniformity: $z$ (parasubicu$\operatorname{lum})=29.5, z($ Pyr $)=4.07, z($ Stel $)=$ 3.36; Fig. 7E; MEC cells from Tang et al., $2014 b, 2015)$. When we compared the preferred phase of identified MEC layer 2 pyramids and identified parasubicular neurons, we found that the parasubicular neurons preferred an earlier theta phase (slightly before the trough; Fig. 7F, left; $p=0.048$, Watson-Williams test for equal circular means: $F=4.34)$. When we included all nonidentified juxta and tetrode recordings of parasubicular and putative MEC layer 2 pyramidal neurons, this difference remained statistically significant (Fig. $7 F$, right; $155^{\circ}$ vs $174^{\circ}, p=$ 0.0000085 , Watson-Williams test for equal circular means: $F=$ 22.7). Because tetrode recordings of MEC layer 2 were assigned their putative cell identity based on their temporal spiking properties, we wondered whether this might have biased the comparison of preferred theta phase. However, two indications suggest that this was not the case: (1) in the identified dataset, we had not excluded any MEC layer 2 neurons, which locked before the trough (Tang et al., 2014b); and (2) even when we applied the same classifier to all parasubicular neurons and only compared MEC layer 2 putative pyramids with parasubicular neurons, which would have been classified as putative pyramids, the difference in preferred phase was still trending toward significance $(p=0.076$, Watson-Williams test for equal circular means: $F=3.21)$.

The strong theta phase locking strength and theta rhythmicity of both parasubicular neurons and layer 2 pyramidal (but not stellate) neurons, as well as the preference of parasubicular neurons to fire at a slightly earlier theta phase $\left(\sim 19^{\circ}\right.$ phase angle, i.e., $\sim 7 \mathrm{~ms}$, assuming an $8 \mathrm{~Hz}$ theta rhythm) than layer 2 pyramidal neurons, are consistent with the idea that parasubicular neurons might impose a feedforward theta-modulated drive onto layer 2 pyramidal neurons.

\section{Discussion}

\section{Unique features of the parasubiculum}

The parasubiculum is distinct from other parahippocampal structures. The elongated shape of the parasubiculum and an almost linear arrangement of neurons differ from other (para)hippocampal structures, such as dentate gyrus, CA3, CA2, CA1, subiculum, pre- 
A

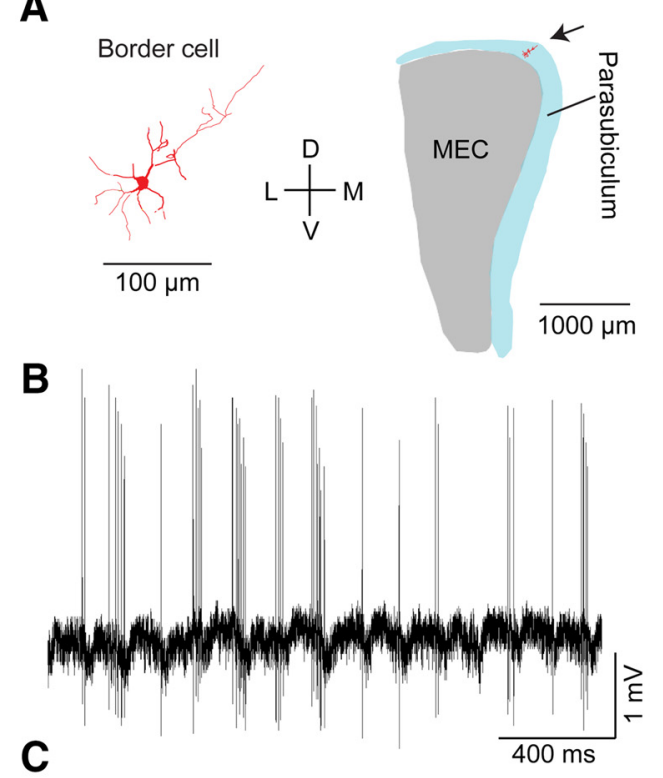

E

Head-direction cell

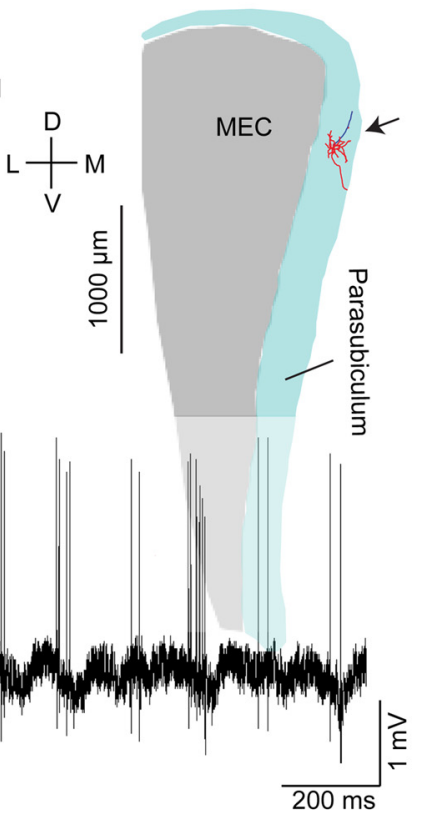

G

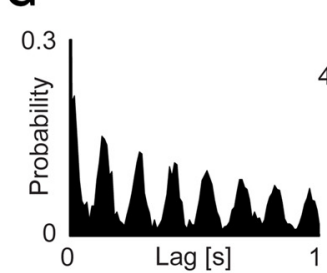

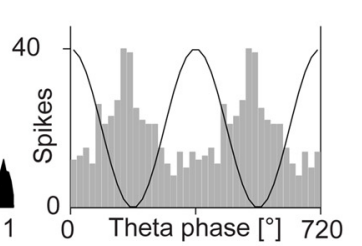

D

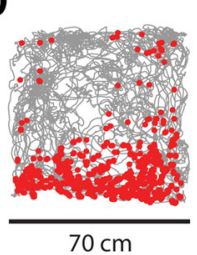

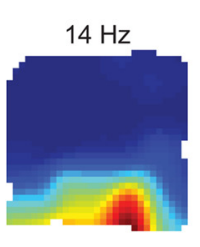

H

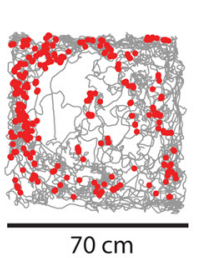

$3 \mathrm{~Hz}$

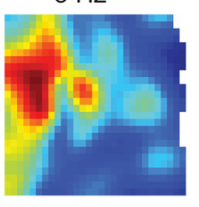

$2.8 \mathrm{~Hz}$

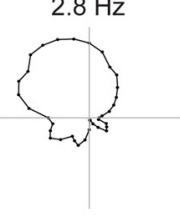

Figure 4. Physiology of identified parasubicular neurons. $A$, Left, Reconstruction of a border cell juxtacellularly recorded and identified in a rat exploring a $2 \mathrm{D}$ environment $(70 \times 70 \mathrm{~cm})$. Red and blue represent reconstructed dendrites and axon, respectively. Scale bar, $100 \mu \mathrm{m}$. Right, Schematic of the location of the cell in the parasubiculum (arrow). The cell is located in the dorsal band of the parasubiculum (blue), close to medial entorhinal cortex (gray). Scale bar, $1000 \mu \mathrm{m}$. B, Representative raw traces of the recorded cell shown in $\boldsymbol{A}$. Note the prominent theta rhythm in LFP and theta-modulated firing of the recorded cell. C, Left, Autocorrelogram of spike discharges for the cell shown in $\boldsymbol{A}$. Right, theta phase histogram of spikes for the cell shown in $\boldsymbol{A}$. For convenience, two repeated cycles are shown. The black sinusoid is a schematic local field potential theta wave for reference. $\boldsymbol{D}$, Spike-trajectory plot (left) and rate map (middle) revealing the border firing. Spike-trajectory plot, Red dots indicate spike locations. Gray lines indicate the rat trajectory. Rate map, Red represents maximal firing rate, value noted above. For this cell, the border score is 0.86 . Right, Polar plot of the cell's head-direction tuning. Value indicates maximum firing rate to the preferred direction. $\boldsymbol{E}-\boldsymbol{H}$, Same as $\boldsymbol{A}-\boldsymbol{D}$ for an identified head-direction cell. D, Dorsal; L, lateral; $\mathrm{M}$, medial; $V$, ventral.

subiculum, and medial or lateral entorhinal cortex (Amaral and Witter, 1989; Cenquizca and Swanson, 2007). Further, absence of directly associated deep layers distinguishes the parasubiculum from the surrounding entorhinal, retrosplenial, and presubicular cortices. The "circumcurrent" axons (as defined by Burgalossi et al., 2011) (Fig. $1 E, F$ ) that traverse the parasubiculum and could thus establish a "global" connectivity are also a unique feature of parasubicular anatomy. Furthermore, the parasubiculum is a preferred target of medial septal inputs and provides the major input to pyramidal neuron patches in layer 2 of medial entorhinal cortex. We observed a larger fraction of spatial and head-directional responses in the parasubiculum than in the adjacent medial entorhinal cortex (Solstad et al., 2008; Tang et al., 2014b).

\section{Comparison with previous work}

Our anatomical analysis agrees with earlier descriptions that large parts of the parasubiculum are situated between the medial en- torhinal cortex and the presubiculum (Amaral and Witter, 1989; Cenquizca and Swanson, 2007). We provide evidence that the parasubiculum extends further laterally than previously thought (van Strien et al., 2009; Boccara et al., 2010) and that this structure might lack direct association with deep layers. The idea that the parasubiculum extends dorsolaterally from the medial entorhinal cortex is based on three observations: (1) staining of cholinergic markers, calbindin immunoreactivity, or cytochrome oxidase activity all delineate a continuous band, which extends dorsolaterally; similarly, both (2) the modular structure of the "large patches" and (3) "circumcurrent" axons extend as a continuous dorsolateral band (Fig. 1) (Burgalossi et al., 2011). Our conclusion that the parasubiculum extends dorsolaterally is strongly supported by recent high-resolution mapping of gene expression in parahippocampal cortices (Ramsden et al., 2015). The authors not only observed that this dorsolateral part is different from medial entorhinal cortex but also showed that it 
A Border cells

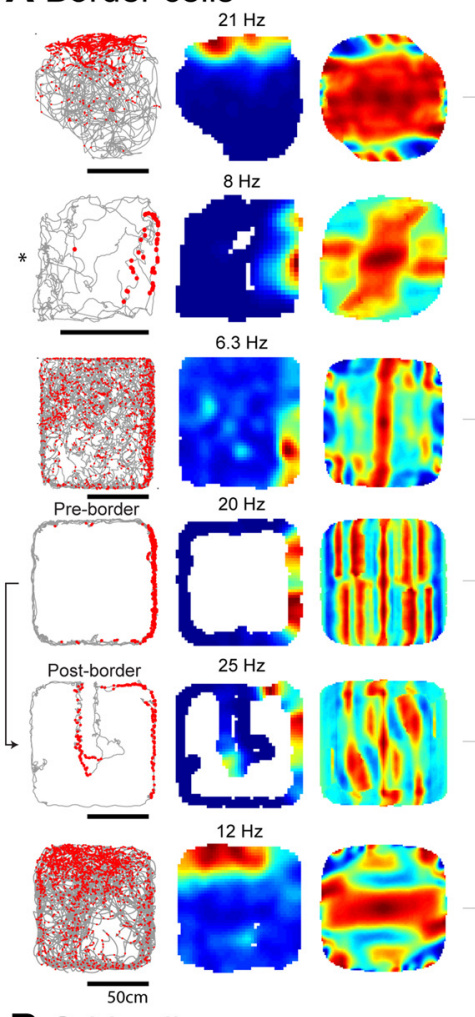

B Grid cells
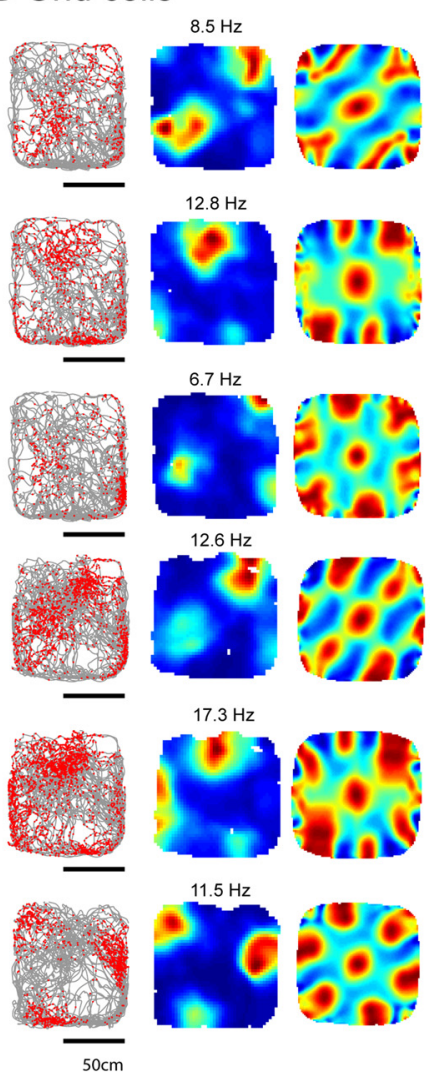
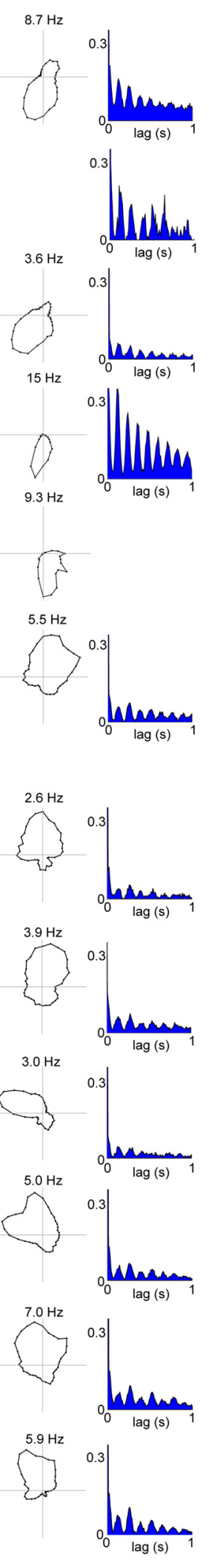

C Head-direction cells
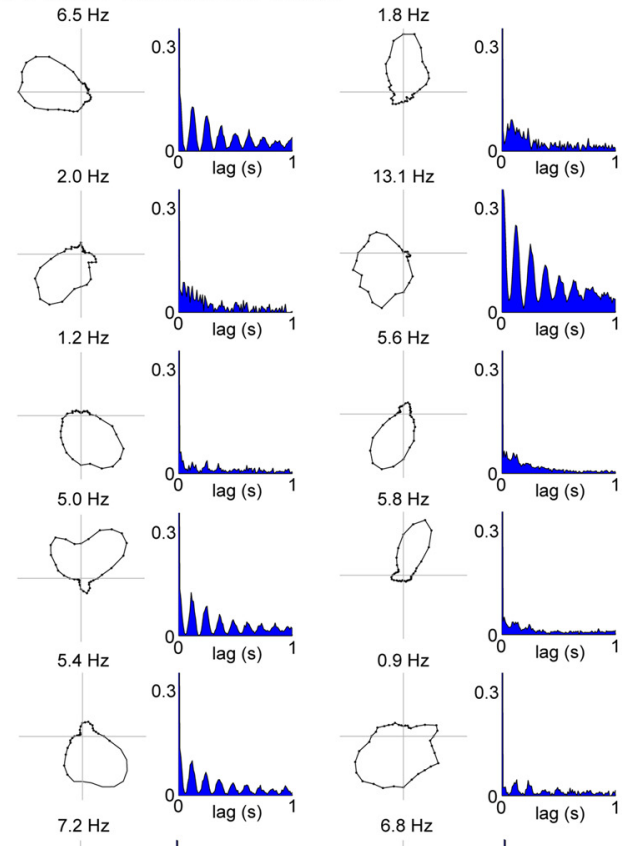

$7.2 \mathrm{~Hz}$

$6.8 \mathrm{~Hz}$
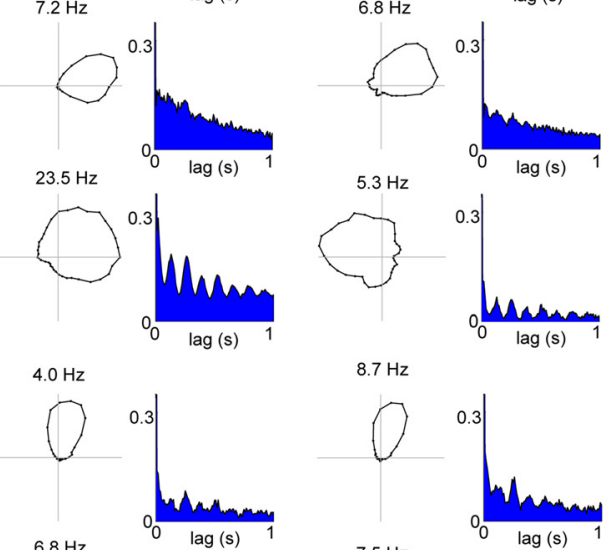

$8.7 \mathrm{~Hz}$
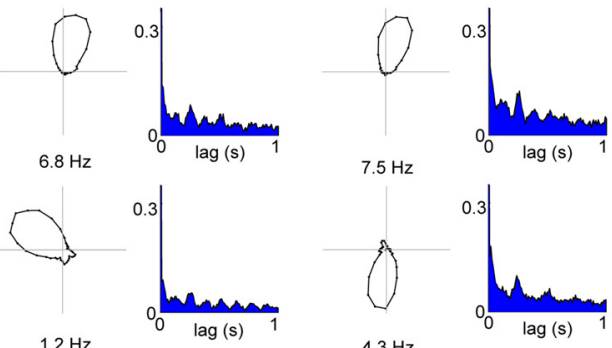

$7.5 \mathrm{~Hz}$
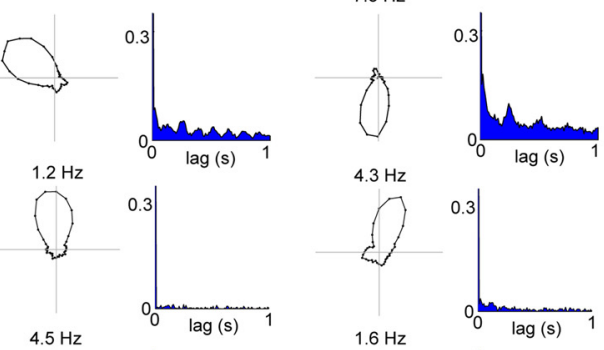

$4.3 \mathrm{~Hz}$
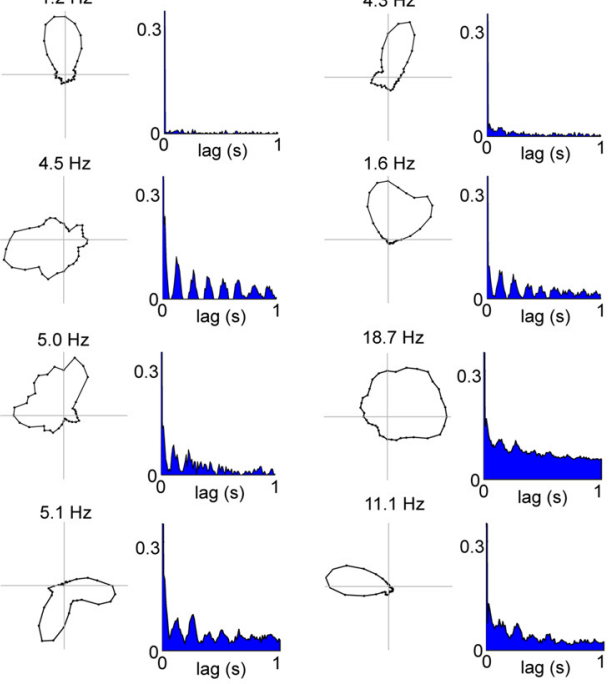

Figure 5. Border, grid, and head-direction firing properties of parasubicular neurons. A, Parasubicular neurons classified as border cells. Left to right, Spike-trajectory plot, rate map, 2D spatial autocorrelation, angular tuning (shown only for head-direction selective cells), and spike autocorrelogram. Numbers above the rate map indicate maximum (Figure legend continues.) 
shares patterns of gene expression with the "classical" medial parasubiculum (Ramsden et al., 2015). The extent to which deep layers were assigned to the parasubiculum varies in the literature. Whereas some studies assigned deep layers to the parasubiculum (Funahashi and Stewart, 1997; Glasgow and Chapman, 2007; Boccara et al., 2010), other work found it difficult to assign adjacent deep layers to either the presubiculum or the parasubiculum based solely on cytoarchitectonic criteria (Mulders et al., 1997). Our assessment that these deep layer neurons should not be viewed as part of the parasubiculum is based on three observations: (1) the shape of dorsal part of the parasubiculum, as revealed by cholinergic markers, calbindin immunoreactivity, or cytochrome oxidase activity, delineates only a "superficial-layer structure" encompassing layers 1-3 (Burgalossi et al., 2011); (2) we did not observe axons from the superficial parasubiculum into adjacent deep cortical layers; and (3) we did not observe axons from the adjacent deep cortical layers into the superficial parasubiculum. The idea that large parts of the parasubiculum lack deep layers is again supported by the gene expression analysis of Ramsden et al. (2015).

Our results agree with previous extracellular recording data that also revealed the presence of spatially modulated neurons in the parasubiculum (Taube, 1995; Cacucci et al., 2004; Boccara et al., 2010; Burgalossi et al., 2011). The present data are also consistent with the study of Boccara et al. (2010), where the authors described grid, border, and head-direction responses in the parasubiculum. Notably, the strong head-direction tuning in the parasubiculum is also consistent with previous (Fyhn et al., 2008; Wills et al., 2010) and more recent work (Giocomo et al., 2014), where sharply tuned headdirection neurons were recorded "near" the dorsalmost border medial entorhinal cortex, hence compatible with a parasubicular origin of these signals (Fig. 1) (Burgalossi et al., 2011). Extracellular recordings have also identified both theta-rhythmic and non-thetarhythmic border cells in this dorsalmost region of MEC (Solstad et al., 2008), where the parasubiculum extends in a narrow stripe above MEC (Fig. 1A). We found that parasubicular border cells lock strongly to the theta rhythm, whereas border cells in MEC layer 2 show only weak entrainment by theta oscillations (Tang et al., 2014 b). Our results show a substantial proportion of spatially irregular cells, in line with previous work (Krupic et al., 2012), which also showed a larger percentage of nongrid, spatially modulated cells in the parasubiculum compared with adjacent MEC. Spatially irregular cells could provide sufficient spatial information for coding the animal's position in space (Zhang et al., 1998; Zhang and Sejnowski, 1999).

\section{Parasubicular discharge properties mirror those of its input structures}

Parasubicular response properties match well with the properties of its inputs. Parasubicular head-direction selectivity is in line with its inputs from anterior thalamus and presubiculum (Taube, 2007). The border responses observed here are in line with subicular inputs, as numerous boundary-vector cells have been observed there (Lever et al., 2009). A prominent aspect of

$\leftarrow$

(Figure legend continued.) firing rate. Numbers above the angular tuning map indicate maximum firing rate at the preferred direction. Scale bar (below the spike trajectory plot), $50 \mathrm{~cm}$. *Border cell recorded in a $70 \times 70 \mathrm{~cm}$ arena. Preborder and Postborder refer to the border test (recording of the same cell before and after the introduction of an additional wall into the arena). B, Parasubicular neurons classified as grid cells (same panels as in $\boldsymbol{A}$ ). C, Parasubicular neurons classified as head-direction cells (see Materials and Methods). Left, Angular tuning. Right, Spike autocorrelogram. Conventions as in $\boldsymbol{A}$.

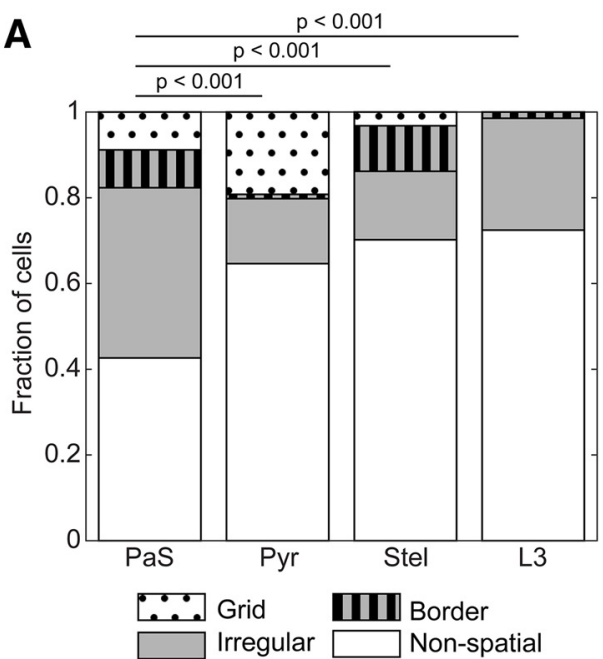

B
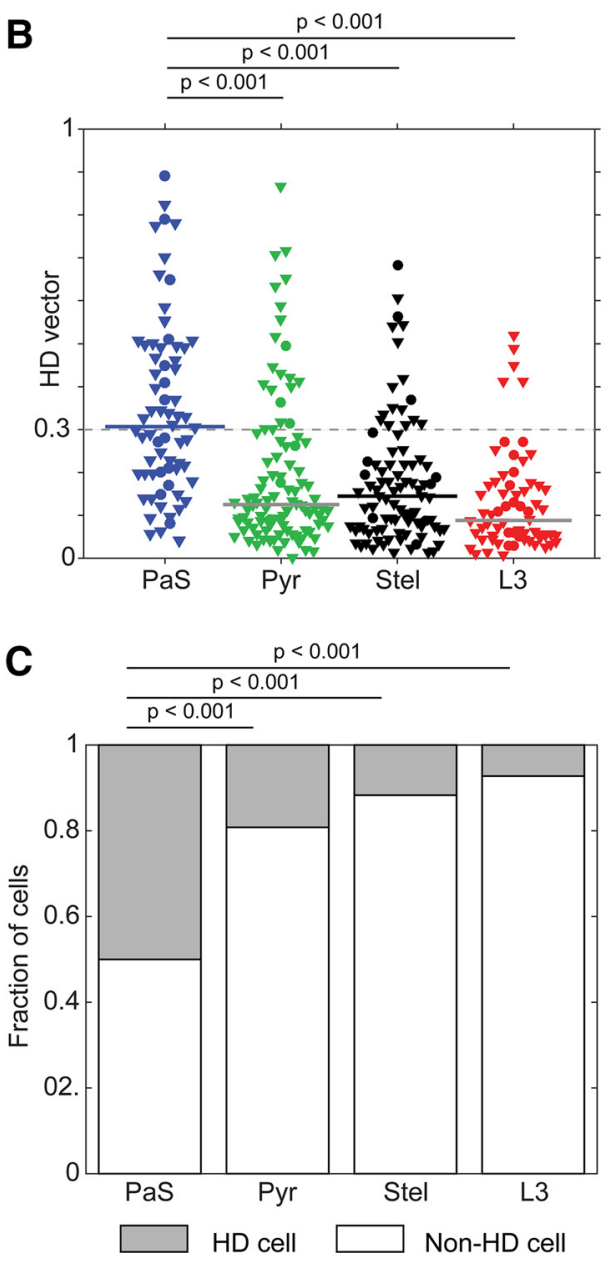

Figure 6. Border and head-direction (HD) firing properties of parasubicular neurons. Data from layers 2 and 3 of MEC come from the work of Tang et al. $(2014 b, 2015)$ and are shown for comparison. A, Comparison offractions of spatial discharges for parasubiculum, MEC L2 pyramidal, MEC L2 stellate, and MEC $L 3$ neurons. Parasubicular neurons show large fraction of significantly spatially modulated cells: grid cells, border cells, and spatially irregular cells ( $\chi^{2}$ test with Bonferroni-Holm correction). $\boldsymbol{B}$, Comparison of HD vector lengths for parasubiculum (blue), MEC L2 pyramidal (green), MEC L2 stellate (black), and MEC L3 (red) neurons. Parasubicular neurons show significantly higher average HD vector length than all others (Mann-Whitney $U$ tests with Bonferroni-Holm correction). Lines indicate medians. Horizontal dotted line at 0.3 indicates the threshold for HD classification. C, Comparison of fractions of HD cells for parasubiculum, MEC L2 pyramidal, MEC L2 stellate, and MEC L3 neurons. Parasubicular neurons show significantly higher percentage of $\mathrm{HD}$ cells ( $\chi^{2}$ test with Bonferroni-Holm correction). 

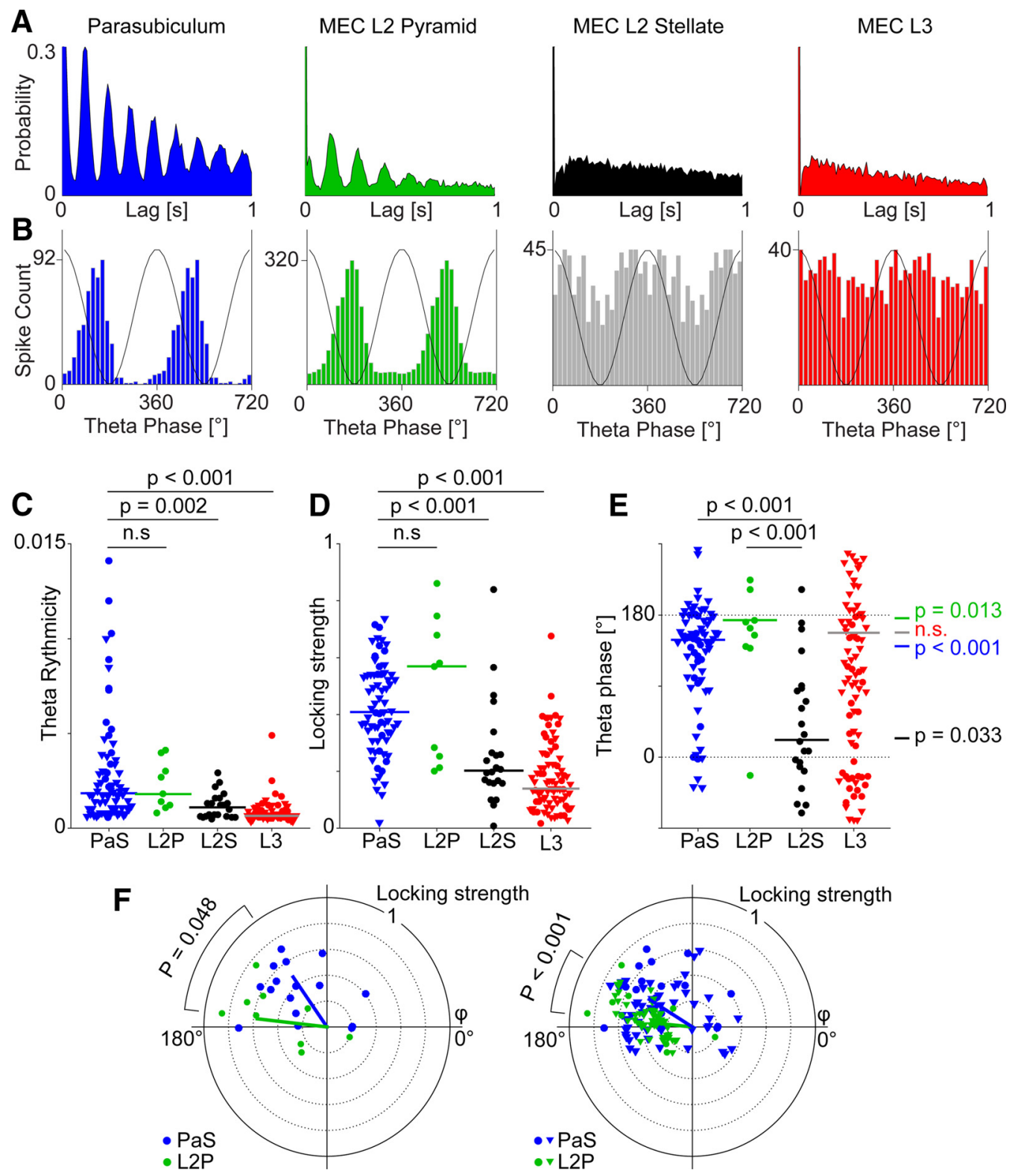

Figure 7. Theta modulation of parasubicular neurons compared with superficial medial entorhinal cortex. Data from layers 2 and 3 of MEC come from the work of Tang et al. (2014b, 2015) and are shown here for comparison. $A$, Representative autocorrelograms of spike discharges of identified neurons recorded from parasubiculum (blue), MEC L2 pyramidal (L2P, green), MEC L2 stellate (L2S, black) and MEC L3 (red) neurons. B, Theta phase histogram of spikes for the neurons shown in $\boldsymbol{A}$. For convenience, two theta cycles are shown. The black sinusoid is a schematic local field potential theta wave for reference. C, Comparison of the power of theta rhythmicity in parasubiculum (blue), MEC L2 pyramid (L2P, green), MEC L2 stellate (L2S, black), and MEC L3 (L3, red) neurons. Parasubiculum neurons show significantly stronger theta rhythmicity than MEC L2 stellate and MEC L3 neurons (Kruskal-Wallis test with Bonferroni correction). Lines indicate medians. D, Comparison of the theta phase locking strength (abbreviated in the figure as "Locking strength") for the neurons shown in C. Parasubicular and MEC L2 pyramidal neurons show significantly higher theta phase locking than MEC L2 stellate and MEC L3 neurons (Kruskal-Wallis test with Bonferroni-Holm correction; significant differences between L2P and L2S have been shown in Ray et al., 2014). Lines indicate medians. $E$, Comparison of the preferred theta phase for the neurons shown in C. Parasubicular and MEC L2 neurons show significant preferred theta phases, whereas MEC L3 neurons do not (Rayleigh test for nonuniformity with Bonferroni-Holm correction: colored $p$ values on the right side; Watson-Williams test for equal means with Bonferroni-Holm correction: black lined $p$ values, top). Colored lines indicate circular means. $\boldsymbol{F}$, Polar plots of preferred theta phase (theta peak $=0^{\circ}$ ) and theta phase locking strength (Rayleigh vector, $0-1$ ) for parasubiculum (blue) and MEC L2 pyramidal (green). Left, Only identified neurons. Right, Identified neurons and tetrode recordings. Dots represent identified neurons. Triangles represent tetrode units. Line indicates mean direction, median strength of locking.

parasubicular activity is the strong theta phase locking and theta rhythmicity of spike discharges. Large membrane-potential theta oscillations have also been recorded from parasubicular neurons in awake animals (Domnisoru et al., 2013). Such strong entrainment may result from the massive septal GABAergic innervation (Fig. $3 A, B$ ) because GABAergic neurons in the medial septum are known to be a key theta pacemaker (Buzsáki, 2002; Hangya et al., 2009; Brandon et al., 2011; Koenig et al., 2011). Cholinergic innervation may also drive parasubicular neurons to depolarized states promoting theta oscillations (Glasgow and Chapman, 2007, 2013).

Does the parasubiculum provide input to the grid system?

Our data suggest a relationship between the parasubiculum and layer 2 of medial entorhinal cortex grid cells (Sargolini et al., 2006; Boccara et al., 2010). Grid cells in the medial entorhinal cortex show strong theta rhythmicity of spiking (Boccara et al., 2010). It is therefore most interesting that the strongly theta- 
rhythmic parasubicular neurons project selectively into layer 2 pyramidal cell patches, where neurons show strong entrainment by the theta rhythm (Ray et al., 2014) and where most grid cells might be located (Tang et al., 2014b). The discharge timing is consistent with an activation/entrainment of layer 2 pyramidal neurons by parasubicular inputs. Parasubicular neurons discharge on average at an earlier theta phase $\left(\sim 19^{\circ}\right.$ phase angle, i.e., $\sim 7 \mathrm{~ms}$ ) than layer 2 pyramidal neurons (Fig. $7 E, F)$. The parasubicular input to layer 2 pyramidal neurons is also remarkable, in light of the sparse excitatory connectivity within layer 2 of medial entorhinal cortex (Couey et al., 2013; Pastoll et al., 2013). Parasubicular inputs could be important for three aspects: (1) for imposing theta rhythmicity on grid responses, and possibly also contributing to their temporal spiking dynamics (Hafting et al., 2008; Mizuseki et al., 2009; Ray et al., 2014; Tang et al., 2014b). (2) Parasubicular head-directional responses could be causally related to downstream grid activity in layer 2 of MEC. Indeed, grid cells have been shown to receive head-directional inputs, and disruptions of head-direction signals also impaired grid cell firing (Bonnevie et al., 2013; Winter et al., 2015). The parasubiculum might be the source of this input, given the large fraction of head-direction cells and the selective output to MEC layer 2 (Fig. 3). (3) Parasubicular border activity could be needed for anchoring entorhinal layer 2 grids to environmental boundaries (Hardcastle et al., 2015). Interestingly, direct projections from border to grid cells have been recently postulated, which might be responsible for determining grid orientation, ellipticity, and stability (Kruge et al., 2014; Hardcastle et al., 2015; Krupic et al., 2015; Stensola et al., 2015). The parasubiculum might be one source of border signals into the entorhinal grid system.

\section{Functional considerations}

What does the parasubiculum do? It seems likely that the parasubiculum plays a role in determining spike timing of downstream neurons relative to theta oscillations. The massive internal connectivity of the parasubiculum by circumcurrent axons is rather unique. These axons connect along the dorsoventral axis of the parahippocampal cortex. As different spatial scales are mapped onto the dorsoventral axis of the medial entorhinal cortex (Brun et al., 2008), we wonder whether these axons ensure that those parasubicular neurons along the dorsoventral axis signaling the same positions (at different spatial scales) fire at the same time relative to the theta cycle. Another peculiar aspect of parasubicular anatomy is the lack of strong direct hippocampal connections (van Strien et al., 2009). Together with the absence of deep layers (the recipient of CA1/subicular back projections in the medial entorhinal cortex) and a thinner layer 1, it seems that the parasubiculum is only poorly connected to the "trisynaptic memory loop" (reciprocal connections between the parasubiculum and postrhinal cortex could, however, provide an indirect pathway) (Agster and Burwell, 2013). We envision that the parasubiculum may function more for providing online spatial information like a pointer ("where am I?") rather than for long-term storage of information (“where was I?"). This pointer hypothesis is consistent with disruption of place cell activity (Liu et al., 2004) and working memory deficits after parasubicular lesions (Kesner and Giles, 1998).

\section{References}

Agster KL, Burwell RD (2013) Hippocampal and subicular efferents and afferents of the perirhinal, postrhinal, and entorhinal cortices of the rat. Behav Brain Res 254:50-64. CrossRef Medline

Amaral DG, Witter MP (1989) The three-dimensional organization of the hippocampal formation: a review of anatomical data. Neuroscience 31 : 571-591. CrossRef Medline

Andersen P, Bliss TV, Skrede KK, Lomo T, Olsen LI (1971) Lamellar organization of hippocampal excitatory pathways. Exp Brain Res 13:222-238. Medline

Barry C, Ginzberg LL, O’Keefe J, Burgess N (2012) Grid cell firing patterns signal environmental novelty by expansion. Proc Natl Acad Sci U S A 109:17687-17692. CrossRef Medline

Bjerknes TL, Moser EI, Moser MB (2014) Representation of geometric borders in the developing rat. Neuron 82:71-78. CrossRef Medline

Blackstad TW (1956) Commissural connections of the hippocampal region in the rat, with special reference to their mode of termination. J Comp Neurol 105:417-537. CrossRef Medline

Boccara CN, Sargolini F, Thoresen VH, Solstad T, Witter MP, Moser EI, Moser MB (2010) Grid cells in pre- and parasubiculum. Nat Neurosci 13:987-994. CrossRef Medline

Bonnevie T, Dunn B, Fyhn M, Hafting T, Derdikman D, Kubie JL, Roudi Y, Moser EI, Moser MB (2013) Grid cells require excitatory drive from the hippocampus. Nat Neurosci 16:309-317. CrossRef Medline

Brandon MP, Bogaard AR, Libby CP, Connerney MA, Gupta K, Hasselmo ME (2011) Reduction of theta rhythm dissociates grid cell spatial periodicity from directional tuning. Science 332:595-599. CrossRef Medline

Brun VH, Solstad T, Kjelstrup KB, Fyhn M, Witter MP, Moser EI, Moser MB (2008) Progressive increase in grid scale from dorsal to ventral medial entorhinal cortex. Hippocampus 18:1200-1212. CrossRef Medline

Burgalossi A, Herfst L, von Heimendahl M, Förste H, Haskic K, Schmidt M, Brecht M (2011) Microcircuits of functionally identified neurons in the rat medial entorhinal cortex. Neuron 70:773-786. CrossRef Medline

Burgess N (2014) The 2014 Nobel Prize in Physiology or Medicine: a spatial model for cognitive neuroscience. Neuron 84:1120-1125. CrossRef Medline

Buzsáki G (2002) Theta oscillations in the hippocampus. Neuron 33: 325-340. CrossRef Medline

Caballero-Bleda M, Witter MP (1993) Regional and laminar organization of projections from the presubiculum and parasubiculum to the entorhinal cortex: an anterograde tracing study in the rat. J Comp Neurol 328: 115-129. CrossRef Medline

Caballero-Bleda M, Witter MP (1994) Projections from the presubiculum and the parasubiculum to morphologically characterized entorhinalhippocampal projection neurons in the rat. Exp Brain Res 101:93-108. Medline

Cacucci F, Lever C, Wills TJ, Burgess N, O'Keefe J (2004) Theta-modulated place-by-direction cells in the hippocampal formation in the rat. J Neurosci 24:8265-8277. CrossRef Medline

Canto CB, Koganezawa N, Beed P, Moser EI, Witter MP (2012) All layers of medial entorhinal cortex receive presubicular and parasubicular inputs. J Neurosci 32:17620-17631. CrossRef Medline

Cenquizca LA, Swanson LW (2007) Spatial organization of direct hippocampal field CA1 axonal projections to the rest of the cerebral cortex. Brain Res Rev 56:1-26. CrossRef Medline

Couey JJ, Witoelar A, Zhang SJ, Zheng K, Ye J, Dunn B, Czajkowski R, Moser MB, Moser EI, Roudi Y, Witter MP (2013) Recurrent inhibitory circuitry as a mechanism for grid formation. Nat Neurosci 16:318-324. CrossRef Medline

Ding SL (2013) Comparative anatomy of the prosubiculum, subiculum, presubiculum, postsubiculum, and parasubiculum in human, monkey, and rodent. J Comp Neurol 521:4145-4162. CrossRef Medline

Domnisoru C, Kinkhabwala AA, Tank DW (2013) Membrane potential dynamics of grid cells. Nature 495:199-204. CrossRef Medline

Fujise N, Hunziker W, Heizmann CW, Kosaka T (1995) Distribution of the calcium binding proteins, calbindin D-28K and parvalbumin, in the subicular complex of the adult mouse. Neurosci Res 22:89-107. CrossRef Medline

Funahashi M, Stewart M (1997) Presubicular and parasubicular cortical neurons of the rat: functional separation of deep and superficial neurons in vitro. J Physiol 501:387-403. CrossRef Medline

Fyhn M, Hafting T, Witter MP, Moser EI, Moser MB (2008) Grid cells in mice. Hippocampus 18:1230-1238. CrossRef Medline

Geneser FA (1986) Distribution of acetylcholinesterase in the hippocampal region of the rabbit: I. Entorhinal area, parasubiculum, and presubiculum. J Comp Neurol 254:352-368. CrossRef Medline

Giocomo LM, Stensola T, Bonnevie T, Van Cauter T, Moser MB, Moser EI 
(2014) Topography of head-direction cells in medial entorhinal cortex. Curr Biol 24:252-262. CrossRef Medline

Glasgow SD, Chapman CA (2007) Local generation of theta-frequency EEG activity in the parasubiculum. J Neurophysiol 97:3868-3879. CrossRef Medline

Glasgow SD, Chapman CA (2013) Muscarinic depolarization of layer II neurons of the parasubiculum. PLoS One 8:e58901. CrossRef Medline

Hafting T, Fyhn M, Bonnevie T, Moser MB, Moser EI (2008) Hippocampus-independent phase precession in entorhinal grid cells. Nature 453:1248-1252. CrossRef Medline

Hangya B, Borhegyi Z, Szilágyi N, Freund TF, Varga V (2009) GABAergic neurons of the medial septum lead the hippocampal network during theta activity. J Neurosci 29:8094-8102. CrossRef Medline

Hardcastle K, Ganguli S, Giocomo LM (2015) Environmental boundaries as an error correction mechanism for grid cells. Neuron 86:827-839. CrossRef Medline

Honda Y, Ishizuka N (2004) Organization of connectivity of the rat presubiculum: I. Efferent projections to the medial entorhinal cortex. J Comp Neurol 473:463-484. CrossRef Medline

Kesner RP, Giles R (1998) Neural circuit analysis of spatial working memory: role of pre- and parasubiculum, medial and lateral entorhinal cortex. Hippocampus 8:416-423. CrossRef Medline

Koenig J, Linder AN, Leutgeb JK, Leutgeb S (2011) The spatial periodicity of grid cells is not sustained during reduced theta oscillations. Science 332: 592-595. CrossRef Medline

Köhler C (1985) Intrinsic projections of the retrohippocampal region in the rat brain: I. The subicular complex. J Comp Neurol 236:504-522. CrossRef Medline

Kruge IU, Waaga T, Wernle T, Moser EI, Moser MB (2014) Grid cells require experience with local boundaries during development: $2014 \mathrm{Neu}-$ roscience Meeting Planner (online 94.01/SS21). Washington, DC: Society for Neuroscience.

Krupic J, Burgess N, O’Keefe J (2012) Neural representations of location composed of spatially periodic bands. Science 337:853-857. CrossRef Medline

Krupic J, Bauza M, Burton S, Barry C, O’Keefe J (2015) Grid cell symmetry is shaped by environmental geometry. Nature 518:232-235. CrossRef Medline

Lever C, Burton S, Jeewajee A, O’Keefe J, Burgess N (2009) Boundary vector cells in the subiculum of the hippocampal formation. J Neurosci 29: 9771-9777. CrossRef Medline

Liu P, Jarrard LE, Bilkey DK (2004) Excitotoxic lesions of the pre- and parasubiculum disrupt the place fields of hippocampal pyramidal cells. Hippocampus 14:107-116. CrossRef Medline

Mitchell SJ, Rawlins JN, Steward O, Olton DS (1982) Medial septal area lesions disrupt theta rhythm and cholinergic staining in medial entorhinal cortex and produce impaired radial arm maze behavior in rats. J Neurosci 2:292-302. Medline

Mizuseki K, Sirota A, Pastalkova E, Buzsáki G (2009) Theta oscillations provide temporal windows for local circuit computation in the entorhinalhippocampal loop. Neuron 64:267-280. CrossRef Medline

Moser EI, Moser MB (2013) Grid cells and neural coding in high-end cortices. Neuron 80:765-774. CrossRef Medline

Moser EI, Kropff E, Moser MB (2008) Place cells, grid cells, and the brain's spatial representation system. Annu Rev Neurosci 31:69-89. CrossRef Medline

Mulders WH, West MJ, Slomianka L (1997) Neuron numbers in the presubiculum, parasubiculum, and entorhinal area of the rat. J Comp Neurol 385:83-94. CrossRef Medline

Pastoll H, Solanka L, van Rossum MC, Nolan MF (2013) Feedback inhibition enables theta-nested gamma oscillations and grid firing fields. Neuron 77:141-154. CrossRef Medline

Paxinos G, Franklin KBJ (2012) Paxinos and Franklin's the mouse brain in stereotaxic coordinates. San Diego: Academic.

Pinault D (1996) A novel single-cell staining procedure performed in vivo under electrophysiological control: morpho-functional features of juxtacellularly labeled thalamic cells and other central neurons with biocytin or Neurobiotin. J Neurosci Methods 65:113-136. CrossRef Medline
Ramsden HL, Sürmeli G, McDonagh SG, Nolan MF (2015) Laminar and dorsoventral molecular organization of the medial entorhinal cortex revealed by large-scale anatomical analysis of gene expression. PLoS Comput Biol 11:e1004032. CrossRef Medline

Ray S, Naumann R, Burgalossi A, Tang Q, Schmidt H, Brecht M (2014) Grid-layout and theta-modulation of layer 2 pyramidal neurons in medial entorhinal cortex. Science 343:891-896. CrossRef Medline

Sargolini F, Fyhn M, Hafting T, McNaughton BL, Witter MP, Moser MB, Moser EI (2006) Conjunctive representation of position, direction, and velocity in entorhinal cortex. Science 312:758-762. CrossRef Medline

Skaggs WE, McNaughton BL, Gothard KM, Markus EJ (1993) An information-theoretic approach to deciphering the hippocampal code. In: Advances in neural processing systems, Vol. 5 (Hanson SJ, Cowan JD, Giles CL, eds). San Mateo, CA: Morgan Kaufmann.

Slomianka L, Geneser FA (1991) Distribution of acetylcholinesterase in the hippocampal region of the mouse: I. Entorhinal area, parasubiculum, retrosplenial area, and presubiculum. J Comp Neurol 303:339-354. CrossRef Medline

Solstad T, Boccara CN, Kropff E, Moser MB, Moser EI (2008) Representation of geometric borders in the entorhinal cortex. Science 322: 1865-1868. CrossRef Medline

Stensola T, Stensola H, Moser MB, Moser EI (2015) Shearing-induced asymmetry in entorhinal grid cells. Nature 518:207-212. CrossRef Medline

Sun C, Kitamura T, Yamamoto J, Martin J, Pignatelli M, Kitch LJ, Schnitzer MJ, Tonegawa S (2015) Distinct speed dependence of entorhinal island and ocean cells, including respective grid cells. Proc Natl Acad Sci U S A 112:9466-9471. CrossRef Medline

Tang Q, Brecht M, Burgalossi A (2014a) Juxtacellular recording and morphological identification of single neurons in freely moving rats. Nat Protoc 9:2369-2381. CrossRef Medline

Tang Q, Burgalossi A, Ebbesen CL, Ray S, Naumann R, Schmidt H, Spicher D, Brecht M (2014b) Pyramidal and stellate cell specificity of grid and border representations in layer 2 of medial entorhinal cortex. Neuron 84: 1191-1197. CrossRef Medline

Tang Q, Ebbesen CL, Sanguinetti-Scheck JI, Preston-Ferrer P, Gundlfinger A Winterer J, Beed P, Ray S, Naumann R, Schmitz D, Brecht M, Burgalossi A (2015) Anatomical organization and spatiotemporal firing patterns of layer 3 neurons in the rat medial entorhinal cortex. J Neurosci 35: 12346-12354. CrossRef Medline

Taube JS (1995) Place cells recorded in the parasubiculum of freely moving rats. Hippocampus 5:569-583. CrossRef Medline

Taube JS (2007) The head-direction signal: origins and sensory-motor integration. Annu Rev Neurosci 30:181-207. CrossRef Medline

van Groen T, Wyss JM (1990) The connections of presubiculum and parasubiculum in the rat. Brain Res 518:227-243. CrossRef Medline

van Groen T, Wyss JM (1992) Projections from the laterodorsal nucleus of the thalamus to the limbic and visual cortices in the rat. J Comp Neurol 324:427-448. CrossRef Medline

van Strien NM, Cappaert NL, Witter MP (2009) The anatomy of memory: an interactive overview of the parahippocampal-hippocampal network. Nat Rev Neurosci 10:272-282. CrossRef Medline

Varga C, Lee SY, Soltesz I (2010) Target-selective GABAergic control of entorhinal cortex output. Nat Neurosci 13:822-824. CrossRef Medline

von Heimendahl M, Rao RP, Brecht M (2012) Weak and nondiscriminative responses to conspecifics in the rat hippocampus. J Neurosci 32: 2129-2141. CrossRef Medline

Wills TJ, Cacucci F, Burgess N, O'Keefe J (2010) Development of the hippocampal cognitive map in preweanling rats. Science 328:1573-1576. CrossRef Medline

Winter SS, Clark BJ, Taube JS (2015) Disruption of the head-direction cell network impairs the parahippocampal grid cell signal. Science 347: 870-874. CrossRef Medline

Zhang K, Sejnowski TJ (1999) Neuronal tuning: to sharpen or broaden? Neural Comput 11:75-84. CrossRef Medline

Zhang K, Ginzburg I, McNaughton BL, Sejnowski TJ (1998) Interpreting neuronal population activity by reconstruction: unified framework with application to hippocampal place cells. J Neurophysiol 79:1017-1044. Medline 